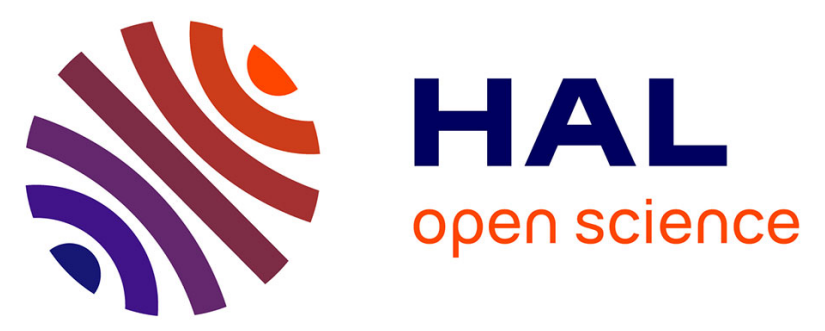

\title{
Radiation and cloud-base lowering fog events: Observational analysis and evaluation of WRF and HARMONIE
}

Carlos Román-Cascón, Carlos Yagüe, Gert-Jan Steeneveld, Gema Morales, Jon A. Arrillaga, Mariano Sastre, Gregorio Maqueda

\section{To cite this version:}

Carlos Román-Cascón, Carlos Yagüe, Gert-Jan Steeneveld, Gema Morales, Jon A. Arrillaga, et al.. Radiation and cloud-base lowering fog events: Observational analysis and evaluation of WRF and HARMONIE. Atmospheric Research, 2019, 229, pp.190 - 207. 10.1016/j.atmosres.2019.06.018 . hal03487272

\section{HAL Id: hal-03487272 \\ https://hal.science/hal-03487272}

Submitted on 20 Dec 2021

HAL is a multi-disciplinary open access archive for the deposit and dissemination of scientific research documents, whether they are published or not. The documents may come from teaching and research institutions in France or abroad, or from public or private research centers.
L'archive ouverte pluridisciplinaire $\mathbf{H A L}$, est destinée au dépôt et à la diffusion de documents scientifiques de niveau recherche, publiés ou non, émanant des établissements d'enseignement et de recherche français ou étrangers, des laboratoires publics ou privés.

\section{(ㅇ)(1) $\$$}

Distributed under a Creative Commons Attribution - NonCommerciall 4.0 International 


\title{
Radiation and Cloud-Base Lowering Fog Events: Observational Analysis and Evaluation of WRF and HARMONIE
}

\author{
Carlos Román-Cascón ${ }^{\mathrm{a}, \mathrm{b}}$, Carlos Yagüe ${ }^{\mathrm{a}}$, Gert-Jan Steeneveld ${ }^{\mathrm{c}}$, Gema Morales ${ }^{\mathrm{d}}$, Jon A. \\ Arrillaga $^{a}$, Mariano Sastre ${ }^{a}$, Gregorio Maqueda ${ }^{a}$ \\ ${ }^{a}$ Dept. Física de la Tierra y Astrofísica. Universidad Complutense de Madrid, Spain \\ ${ }^{b}$ Laboratoire d'Aérologie, University of Toulouse, CNRS, France \\ ${ }^{c}$ Meteorology and Air quality Section. Wageningen University, The Netherlands \\ ${ }^{d}$ Agencia Estatal de Meteorología (AEMET), Madrid, Spain
}

\begin{abstract}
Most of the effects caused by fog are negative for humans. Yet, numerical weather prediction (NWP) models still have problems to simulate fog properly, especially in operational forecasts. In the case of radiation fog, this is partially caused by the large sensitivity to many aspects, such as the synoptic and local conditions, the near-surface turbulence, the aerosol and droplet microphysics, or the surface characteristics, among others. This work focuses on an interesting 8-day period with several alternating radiation and cloud-base lowering (CBL) fog events observed at the Research Centre for the Lower Atmosphere (CIBA) in the Spanish Northern Plateau. On the one hand, radiation fog events are associated with strong surface cooling leading to high stability close to the surface and low values of turbulence, giving rise to shallow fog. The evolution of this type of fog is markedly sensitive to the dynamical conditions close to the surface (i.e., wind speed and turbulence). On the other hand, CBL fog presents deeper thickness associated with higher values of turbulence and less stability. Subsequently, we evaluated the fog-forecasting skill of two mesoscale models (WRF and HARMONIE) configured as similar as possible. Both models present more difficulties simulating radiation fog events than CBL ones. However, the duration and vertical extension of the CBL fog events is normally overestimated. This extended-fog avoids the surface radiative cooling needed to simulate radiation fog events formed the following nights. Therefore, these periods with alternating CBL and radiation fog are especially challenging for NWP models.
\end{abstract}

Keywords:

Fog, radiation, cloud-base-lowering, WRF, HARMONIE, model skill 


\section{Introduction}

Fog affects human life in many forms. Only a few impacts are positive, like the extra water supply in freshwater-poor regions using fog collectors (Shanyengana et al., 2002; Roco et al., 2018) or the moisture (and nutrients) source for some plants (Azevedo and Morgan, 1974; Dawson, 1998). However, all the other fog effects are negative and undesired by humans. The terrestrial, aerial and maritime transportation is difficult and often dangerous under foggy conditions due to the associated reduction in visibility (Fabbian et al., 2007; Fu et al., 2010; Bartok et al., 2012). Thus, the economic costs of fog (accidents, flights cancellations, etc.) are estimated to be similar than those associated with the destruction caused by tornadoes (Gultepe et al., 2007). Moreover, the combination of pollution and fog causes severe and significant problems for human health in some areas, increasing, for example, the hospital visits for asthma episodes (Tanaka et al., 1998).

Even having all these negative influences on humans, the prediction of fog is still a main challenge for the meteorological services (Zhou et al., 2012; McCabe et al., 2016) since numerical weather prediction (NWP) models still have problems simulating this phenomenon (Steeneveld et al., 2015). These fog-forecasting difficulties are affected by different aspects. The first issue is related to the own complexity of fog, which forms as result of a delicate combination of appropriate surface dynamics and turbulence (e.g., Zhou and Ferrier, 2008), radiation (e.g., Funk, 1962), aerosols and droplets chemistry and microphysics (e.g., Mohan and Payra, 2009), large-scale synoptic conditions (e.g., Hyvärinen et al., 2007) and/or specific interactions with the local features, such as topography (e.g., Hang et al., 2016). In many cases, global models have scales that are not appropriate to reproduce fog, and the use of mesoscale ones is encouraged (Teixeira, 1999). Thus, mesoscale NWP models need to simulate correctly all these physical processes to perform successful simulations of fog. However, the fog forecasting can be also affected by issues related to the model itself: possible errors in initial and boundary conditions (e.g., Bergot and Guedalia, 1994; Hu et al., 2014), appropriate spin-up times (e.g., Román-Cascón et al., 2016a), limitations in the vertical/horizontal resolution (e.g., Philip et al., 2016; Boutle et al., 2016) or inappropriate parameterizations of sub-grid scale processes (e.g., Román-Cascón et al., 2012; Chaouch et al., 2017). These are some of the reasons why in other cases, the use of 1D models and statistical downscaling techniques are also used, especially in predictions needed at specific points, e.g., in airports (Cornejo-Bueno et al., 2017). Since fog can form over land or sea following different processes, the ability of the model simulating fog will also differ depending on the fog type.

On the one hand, the most common (and probably studied) fog type is radiation fog, formed as a result of the surface radiative cooling during the night (Bergot et al., 2007; Gultepe et al., 2007). Many observational and/or modelling studies have focused on this type of fog (e.g., Terradellas et al., 2008; Van der Velde et al., 2010; Bergot, 2013; Price et al., 2018, among many others), but models still have problems simulating it, especially when its formation is not imposed by the local topography (Müller et al., 2010). The characteristics of radiation fogs are variable, from short-lived, not-mixed and shallow fog events of a few meters to persistent, well-mixed and deep events of several hundreds of meters (Duynkerke, 
1999; Román-Cascón et al., 2016b). Radiation fog can start its dissipation from the lower layers close to the surface or from the upper ones following different mechanisms, which are normally associated with increases in temperature, wind or turbulence. Several radiation fog events are often dissipated or elevated from the surface after sunrise when the daytime convection starts. This process can lead to clear skies after some minutes/hours, but in some cases the fog is transformed into low stratus clouds that can persist in the area even during the whole daytime.

On the other hand, the so-called cloud-base lowering (CBL) fog forms as the result of the lowering of the base of low-stratus clouds. CBL fog events are common in many areas of the world (Goodman, 1977; Tardif and Rasmussen, 2007; Van Schalkwyk and Dyson, 2013) and have been exhaustively studied in coastal and offshore areas (e.g., Oliver et al., 1978; Bari et al., 2015). However, they are also formed over land (Duynkerke and Hignett, 1993; Koračin et al., 2001; Roco et al., 2018), where they have been less studied. In some cases, $\mathrm{CBL}$ fog is observed after the descending of low-stratus clouds that were previously fog (process commented in the previous paragraph). Thus, these periods are characterized by: 1) radiation fog; 2) low-stratus clouds formed by fog dissipation at the surface or fog elevation and; 3) CBL fog formed by the descending of low stratus. Unlike radiation fog, CBL fog does not require a net radiative cooling at the surface for its formation; in fact, the own existence of the stratus cloud can dampen this cooling. These periods with alternating radiation-CBL fog are common in many areas; however, literature is scarce on their observational analysis (e.g., Dupont et al., 2012, 2018), as well as in the evaluation of their simulation by models considering their specific fog formation processes.

This lack of research is the main motivation of this study. The first objective of this work aims to better understand the conditions in which CBL and radiation fog events form through an exhaustive observational analysis of their features. In this sense, we have analysed a particular period of eight days characterized by alternating CBL and radiation fog at the Research Centre for the Lower Atmosphere (CIBA) site in the Spanish Northern Plateau during January 2016. The instrumentation specifically deployed for investigating the development of fog in the site allows this study. On the other hand, it results especially interesting to evaluate state-of-the-art mesoscale models simulating these fog events of different characteristics, as well as to quantify their skill simulating the key near-surface meteorological variables controlling the fog evolution. For this aim, we analyse how this period is simulated by the Weather Research and Forecasting (WRF) model and the HIRLAM ALADIN Research on Mesoscale Operational NWP In Euromed (HARMONIE) model set with the AROME configuration and with similar configuration than WRF. Hence, the second objective of this work is focused on detecting the strengths and weaknesses of these models under different fog-type specific conditions. These findings are expected to be valuable to improve the operational forecasting of fog, as well as the model development.

This work is organised as follows: Section 2 presents the observational data used to characterize the events at the site, the configuration of the models and an introduction to the analysed period. Section 3 presents an exhaustive observational description and analysis of the model skill for each fog event. Section 4 gathers an overview of the model skill for all the events, discussing the results obtained for CBL and radiation fog. Finally, the main 
findings are summarised in Section 5.

\section{Observational data, models and period}

\subsection{Observational data}

The observational data analysed and used for the model evaluation in this study have been collected at CIBA site during the period comprising from 19 to 27 January 2016. This site (41 $48.92^{\prime} \mathrm{N} ; 4^{\circ} 55.92^{\prime} \mathrm{W}, 840 \mathrm{~m}$ above sea level) is located over Los Montes Torozos, an elevated and extended plateau of $800 \mathrm{~km}^{2}$ situated over the large and wide Spanish Northern Plateau. A more complete description of this site is provided in Cuxart et al. (2000), while the fog climatology of the site was studied in Román-Cascón et al. (2016a). This work showed how most of the radiation-fog events at CIBA are formed between November and February. The site is prone to the formation of radiation fog, in many cases alternated with low-stratus clouds and CBL fog, affecting considerably to the nearby airport of Valladolid (Guijo-Rubio et al., 2018). Table 1 shows information about the instruments measuring the different variables. Note how in this study we analyse, among other variables, the observed fog thickness calculated using data from visibilimeters installed at 2, 30, 70 and $100 \mathrm{~m}$. Hence, its uncertainty is determined by the distance between visibilimeters. For example, if the fog is observed at $30 \mathrm{~m}$ but not a $70 \mathrm{~m}$, it indicates a fog thickness between 30 and 70 $\mathrm{m}$. When the fog is observed at the four levels, we can only determine that the minimum fog thickness was $100 \mathrm{~m}$.

\subsection{Models}

Two mesoscale models have been used to simulate this period: the WRF-ARW (Weather Research and Forecasting Advanced Research WRF) model (version 3.7.1) (Skamarock et al., 2005) and the non-hydrostatic convection-permitting HARMONIE (HIRLAM ALADIN Research on Mesoscale Operational NWP In Euromed) model version 40h1.1 set with the AROME configuration (Bengtsson et al., 2017). Both models were configured as similar as possible: one domain of 300x300 grid points with $2.5 \mathrm{~km}$ of grid spacing and approximately the same vertical levels positioned at similar heights (both models with 4 levels below $100 \mathrm{~m}$ and 7 below $200 \mathrm{~m}$ ). Although the HARMONIE-AROME model does not permit to be fully customizable, some changes have been done for the comparison: a smaller domain than the operational model, no assimilation, boundary conditions applied every 3 hours and a model start not connected to previous forecasts. The WRF-ARW model has been configured with similar settings than HARMONIE-AROME (see Table 2).

A set of 7 simulations were performed, starting at 1200 UTC of each day from 18 to 25 January 2016 and running for $48 \mathrm{~h}$. In order to evaluate the ability of the models forecasting radiation fog with certain lead time, we analyse only the simulation period from $+24 \mathrm{~h}$ to +48 h, i.e., the second forecasted day. In fact, a previous study noted a better skill for the WRF model for the second forecasted day than the first one, probably due to spin-up issues (Román-Cascón et al., 2016a). Subsequently, a simulation composite was made with the 7 simulated days. Therefore, some discontinuities in the composite could be expected at 1200 
UTC of each day, but in fact, these discontinuities are not clearly observed, which is a good indicator of the consistency between the runs performed on consecutive days.

A great part of the analyses shown hereinafter compares observed and simulated visibility. While direct visibility data are provided by the BIRAL SWS-100 visibilimeters, the visibility in the models have been calculated from liquid water content (LWC) output at the model levels. Since no information about the droplet spectra was available from the models, the LWC-visibility relationship given in Kunkel (1984) (equations 4 and 11) was used.

\subsection{Analysed period}

The synoptic situation over the Iberian peninsula during the period from 19 to 27 January 2016 was especially appropriate for the formation of radiation fog in predisposed areas over the Spanish Northern Plateau. A weak surface-pressure gradient existed during most part of the period, with a high pressure system first over central Europe and then extending towards the south. At $500 \mathrm{hPa}$, a relatively warm air mass existed during the whole period, except for days 20, 26 and 27 (supplementary figure 1). This situation led to weak winds (supplementary figure 3c) and to nocturnal surface cooling (supplementary figure 3a) which caused the formation of several fog events over the area. An overview of the visibility during the whole period is shown in supplementary figure 2a (note that each event will be shown with more detail in the results section). Six different events have been identified from the dark-grey colours in this figure, which represents horizontal visibility lower than 1 $\mathrm{km}$ obtained from the four visibilimeters installed at the site (Table 1), i.e., fog is detected when grey colour is observed at the lowest level $(2 \mathrm{~m})$. The fog events were separated into individual cases when the visibility at $2 \mathrm{~m}$ above ground level (agl) was higher than 1 $\mathrm{km}$ during at least $6 \mathrm{~h}$ between two consecutive events. From this detection, three events (event 1, 4 and 5) have been classified as radiation fog, formed as the result of the radiative cooling at the surface. The other three events (2,3 and 6) showed the typical behaviour of cloud-base lowering (CBL) fog, resulting from the descending of low-cloud base. All the events have been simulated with the WRF and HARMONIE models (supplementary figure $2 \mathrm{~b}$ and c respectively), set with similar configurations (Table 2). The observed features are different for each fog event (main characteristics of the six fog events are shown in Table 3), as occurs for the model skill simulating fog. The model biases (differences between model and observed values) of the six fog events are summarised in Table 4 . These differences among the events motivate an exhaustive individual analysis for each event rather than a global analysis and evaluation, which could lead to wrong or inappropriate conclusions. Below, we show this case-by-case analysis, firstly with an observational description of each fog event and the associated surface variables and secondly with the analysis of the model skill for each specific event. 


\section{Observational analysis and model skill}

\subsection{Event 1. Radiation fog (20 Jan 00:40 - 20 Jan 04:23 UTC)}

\section{Observational description}

This fog event (Figure 1a) is a short $(3.7 \mathrm{~h}$ ) and shallow (mean thickness of $34 \mathrm{~m}$ ) pure radiation fog (Table 3) formed due to the surface radiative cooling during the afternoon preceding its formation. Mist (visibility between 1 and $5 \mathrm{~km}$ ) was observed at $2 \mathrm{~m}$ around 2200 UTC before the fog formation (Figure 1a). The fog was formed from the surface at 0040 UTC, growing up to more than $30 \mathrm{~m}$ (and less than $70 \mathrm{~m}$ ) in a few minutes. Eventually, the fog grew up to the 70-m level for a short period around 0120 UTC but it remained with 30-70-m depth during the majority of the event. The fog dissipation started from above a few minutes before the surface dissipation at 0300 UTC. Subsequently, the visibility remained low at the surface (mist, less than $5 \mathrm{~km}$ ) but lower than $1 \mathrm{~km}$ at the $30-\mathrm{m}$ level, i.e., the fog was transformed into very-low and shallow clouds close to the surface. Then, these very-low clouds descended to the surface level $(2 \mathrm{~m})$ again for almost one hour, until the final fog dissipation at 0415 UTC approximately, well before sunrise. The fog did not re-appear during the following daytime.

Figure 2 shows the associated surface variables during this event. The 2-m temperature $\left(T_{2}\right)$ remained below $0{ }^{\circ} \mathrm{C}$ (mean of $-0.84{ }^{\circ} \mathrm{C}$ ) during the whole fog event, with a surfacebased temperature inversion that persisted during the event (see temperature at different levels in Figure 2a), i.e. no effective mixing was observed in the lowest layers (the mean temperature difference between 10 and $2 \mathrm{~m}$ was $0.63{ }^{\circ} \mathrm{C}$, see Table 3 ). These conditions were associated with relatively low values of the $10-\mathrm{m}$ wind $\left(W S_{10}\right)$ and turbulent kinetic energy (TKE) (Figure 2b and d), with a mean $W S_{10}$ of $1.34 \mathrm{~m} \mathrm{~s}^{-1}$ and mean $T K E$ of 0.05 $\mathrm{m}^{2} \mathrm{~s}^{-2}$ (Table 3) during the fog event. $W S_{10}$ and $T K E$ only increased between 0100 and 0200 UTC, when the fog eventually evolved to $70 \mathrm{~m}$ agl. A similar but more intense increase in wind speed and turbulence started at $0430 \mathrm{UTC}$, just after the final fog dissipation. $q_{2}$ ranged between $4 \mathrm{~g} \mathrm{~kg}^{-1}$ before the event and $3.76 \mathrm{~g} \mathrm{~kg}^{-1}$ during the fog due to the water vapour transformation into liquid water (Figure 2c), highly influenced by $T_{2}$. Note how the pre-fog/fog $q_{2}$ difference was quite small in this event compared to the other events. That is, the fog was formed after the condensation of a small amount of water vapour.

\section{Model skill}

WRF is not able to simulate the fog at all (Figure 1b). However, the simulated surface variables (blue thick lines in Figure 2) present relatively low biases (see Table 4 for mean biases). We think that the reasons for the lack of fog simulation could be related to some microphysics limitations under freezing conditions or due to the insufficient number of vertical layers close to the surface for this very shallow event. A similar limitation for fog forecasting under freezing conditions has also been observed in previous works using the WRF model (Van der Velde et al., 2010). 
HARMONIE is not able to simulate the fog neither (Figure 1c), but it simulates mist, with a decrease in visibility until values between 1 and $5 \mathrm{~km}$ close to the surface, approximately at the same time of the observed fog. However, the model overestimates the rest of surface variables during most part of the event (see red thick lines in Figure 2 and mean biases in Table 4). The overestimation in $T_{2}, W S_{10}$ and $T K E$ (quite substantial) seemed to be related to the inability of the model producing more LWC close to the surface until the values needed to produce fog. However, even with these biases in surface variables, this model was able to simulate more realistic conditions of low visibility than WRF.

\subsection{Event 2. CBL fog (20 Jan 23:09 - 21 Jan 01:09 UTC)}

\section{Observational description}

Fog event 2 (Figure 3a) is classified as a short-lived $(2 \mathrm{~h})$ and deep ( $>100 \mathrm{~m}$ thickness) CBL fog (Table 3) formed as the result of the descending of low stratus clouds. Visibility lower than $1 \mathrm{~km}$ was firstly observed at all the levels above $2 \mathrm{~m}$ at 2300 UTC. 30 minutes later the fog was also observed at the surface level, lasting during $2 \mathrm{~h}$ with a thickness of more than $100 \mathrm{~m}$. During the next morning, visibility lower than $1 \mathrm{~km}$ was observed at the levels of 70 and $100 \mathrm{~m}$ around 0700 UTC (see supplementary figure 2a), which could be linked to the CBL formation mechanism of the next fog event (event 3).

Figure 4 shows the associated surface variables during the event (mean values in Table 3 ). The deep character of this fog agrees with the relatively high values of $T K E$ (mean of 0.14 $\mathrm{m}^{2} \mathrm{~s}^{-2}$ ) and the temperature difference between 10 and $2 \mathrm{~m}$ (mean of $0.24{ }^{\circ} \mathrm{C}$ ), leading to moderate mixing close to the surface (Table 3), which allowed the vertical extension of the fog. $T_{2}$ remained higher than the precedent event during the whole fog and pre-fog conditions (around $5-5.5{ }^{\circ} \mathrm{C}$, Figure $\left.4 \mathrm{a}\right)$. A very shallow $(1.5$ to $10 \mathrm{~m})$ and weak surface thermal inversion was present, but the temperature remained lower at the levels of 50 and $85 \mathrm{~m}$ than at the surface levels. This was caused by the existence of low stratus at higher levels, which dampened the radiative cooling at the surface. The temperature at all the levels increased during the fog event probably due to a warm advection. Mean $W S_{10}$ during the event was $1.73 \mathrm{~m} \mathrm{~s}^{-1}$, quickly increasing towards the fog dissipation, which was clearly caused by this wind speed increase (Figure $4 \mathrm{~b}$ ). This event presents moderate values of $T K E$ (mean of $0.14 \mathrm{~m}^{2} \mathrm{~s}^{-2}$ (Table 3)) and values of almost $0.5 \mathrm{~m}^{2} \mathrm{~s}^{-2}$ during the dissipation stage (Figure 4d). In contrast to expected and observed in event $1, q_{2}$ (Figure 4c) did not decrease during the fog event and a weak increase of $0.2 \mathrm{~g} \mathrm{~kg}^{-1}$ was even observed. This was probable due to the commented warm and more humid advection from SW, inferred from synoptical maps (supplemental material 2) and also observed from backward trajectory models (not shown).

\section{Model skill}

Both models clearly overestimate the fog duration (Figure $3 \mathrm{~b}$ and c). Since observations are absent above $100 \mathrm{~m}$, the simulated height cannot be evaluated in this case, but the model simulates a fog layer of 400-500 m. 
WRF simulates a too-early fog onset ( $-8 \mathrm{~h}$ of bias, see Table 4$)$, although a transitory dissipation is observed close to the surface around 2200 UTC (Figure 3b) to come back at 0000 UTC, a similar time as the observed fog formation. The CBL mechanism was correctly simulated. The model also simulates the dissipation of the fog during nighttime (2 h later than observed, Table 4) through a transformation into low clouds, which agrees with the observations (Figure $3 \mathrm{~b}$, see also supplementary figure $2 \mathrm{~b}$ to better observe the post-fog period). Mean biases for the surface variables are shown in Table 4: $T_{2}$ is clearly underestimated by the model (bias of $-2.2^{\circ} \mathrm{C}$, see also Figure $\left.4 \mathrm{a}\right)$, as well as $q_{2}(-0.76 \mathrm{~g}$ $\mathrm{kg}^{-1}$, Figure 4c). The underestimation in $T_{2}$ also causes enhanced condensation and too high values of LWC, giving rise to a too deep fog. The evolution of $W S_{10}$ is not well simulated, like the observed wind-speed increase around 0100 UTC linked to the dissipation (Figure 4b, blue line). TKE is slightly overestimated during the pre-fog and first part of the fog, but underestimated at the dissipation stage (Figure 4d), leading to an overall $T K E$ underestimation $\left(-0.16 \mathrm{~m}^{2} \mathrm{~s}^{-2}\right)$ during the fog event.

HARMONIE also simulates a too persistent fog at the surface, clearly overestimating its duration (formation $5 \mathrm{~h}$ anticipated and dissipation $10 \mathrm{~h}$ delayed, see Table 4 ). The model also underestimates considerably $T_{2}$ and $q_{2}$ (see Table 4 ). $W S_{10}$ and $T K E$ are underestimated during the fog (Table 4) and the observed wind speed and turbulence increases linked to the fog dissipation were not simulated (Figure $4 \mathrm{~b}$ ). This underestimation in wind and turbulence avoided the fog dissipation by the model, leading to a too-long event. The skill of HARMONIE simulating these key parameters for fog evolution is, in general, worse than that of WRF in this case.

\subsection{Event 3. $C B L$ fog (21 Jan 18:32 - 23 Jan 10:47 UTC)}

\section{Observational description}

This event (Figure 5a) is classified as a CBL fog persisting during almost the whole daytime at the surface with a total duration of over $40 \mathrm{~h}$. The fog was present at all the visibilitymeasurement levels during a great part of its duration, but it also presents some periods with a thickness lower than $100 \mathrm{~m}$ (Figure 5a). The fog was formed as the result of the lowering of low clouds (Figure 5a before 1800 UTC of day 21). During the whole event, the fog is only eventually dissipated for short periods close to the surface $(2 \mathrm{~m})$ and for that reason, this long event is considered as a unique one. The fog of the previous night (event 2) was converted in low clouds, descending during the day 21 and reaching the ground at 1830 UTC (fog onset). 2-m visibility increased up to values higher than $1 \mathrm{~km}$ but lower than 5 $\mathrm{km}$ (mist) for short periods during the first night, while the fog was totally dissipated at the surface around 1400 UTC of day 22, but only for a few minutes. The fog behaviour was more irregular during the second night, with observed dissipation at higher levels (for example between 2100 UTC and 0000 UTC, Figure 5a). Later, the fog was dissipated at all the measurement levels at 0200 UTC approximately. The fog was again observed at 0600 UTC through a new CBL process. Then the fog dissipated completely at 1047 UTC from the layers close to the surface. 
Figure 6 shows the associated surface variables during the event. The mean $T_{2}$ was relatively high during this event (mean of $8.76{ }^{\circ} \mathrm{C}$ ) in comparison with other events (Table 3). The fog onset did not correspond with a progressive surface cooling but with a temperature increasing along the evening previous to the fog formation. The CBL process of fog formation was linked to the observed decrease in $W S_{10}$ before the fog onset (Figure 6b). The temperature during the fog period continued increasing during the daytime of 22 January, but the temperature could not decrease during the first night with fog (Figure 6a), due to the thick foggy layer. Finally, the temperature increased after sunrise of day 22 (around 0730 UTC), with the maximum temperature linked to the short-lasting period without fog at the surface at around 1400 UTC.

This fog can be divided into two parts, with the middle of the event in the short-lived dissipation observed around 1400 UTC. The first part of the fog is characterized by relatively high $W S_{10}$ (Figure 6b), probably associated with a more efficient mixing of the fog (almost always observed at the uppermost visibilimeter at $100 \mathrm{~m}) . W S_{10}$ during this first part oscillated between 1 and $3 \mathrm{~m} \mathrm{~s}^{-1}$ (Figure 6b). However, the second part of the fog was characterized by weaker $W S_{10}$, always less than $1.5 \mathrm{~m} \mathrm{~s}^{-1}$ and with marked oscillations (Figure 6b). This could cause the apparition and dissipation of the fog at the surface during this second night since the mixing was not enough to produce a well-developed fog (see Figure 5a). Regarding the observed turbulence values, the same conclusions can be extracted from the analysis of Figure $6 \mathrm{~d}$, with values of the order of $0.1 \mathrm{~m}^{2} \mathrm{~s}^{-2}$ during the first part (thicker fog) and $0.01 \mathrm{~m}^{2} \mathrm{~s}^{-2}$ during the second part (shallower) of the event, in accordance with results found in Román-Cascón et al. (2016b). On the other hand, the mean $q_{2}$ during the event was $7.54 \mathrm{~g} \mathrm{~kg}^{-1}$ with lower values during the first part of the event (Figure 6c) due to thicker fog and lower visibility values (the fog was denser during this part, visibility values are not shown). However, the second part of the fog was characterised by an increase in $q_{2}$ (Figure 6c) associated with less dense fog (enhanced visibility, less LWC and therefore larger $q_{2}$ values).

\section{Model skill}

WRF simulates relatively well the fog onset following a CBL process and also the fog dissipation for this long-lasting fog event (Figure 5b, onset bias of $-1 \mathrm{~h}$ and dissipation bias of $+1 \mathrm{~h}$, see Table 4). The surface dissipation observed during the day 22 at 1400 UTC is well captured by the model, but its duration is overestimated (it lasts a few minutes in the observations and $4.5 \mathrm{~h}$ in the model). Besides, the model dissipates the fog at all levels while this short dissipation only extended up to the 30-m level according to the observations (Figure 5a). The process of final dissipation is also quite well simulated by the model, including the cloud structures formed in the lowest layers (it cannot be evaluated above $100 \mathrm{~m} \mathrm{agl}$ ). Globally, the WRF model simulates correctly this event, except for the overestimation in the duration of the fog dissipation in the middle of the event. Regarding the fog thickness, the model simulates a fog layer of $300-800 \mathrm{~m}$ during the first part and $50-400 \mathrm{~m}$ fog during the second part of the event. It is impossible to evaluate the fog thickness with the available data, however, the tendency of thickness decreasing agrees with 
the observations.

HARMONIE also simulates a CBL process associated with the fog formation, but delaying the fog onset and dissipation (Figure $5 \mathrm{c}$, onset bias of $+4 \mathrm{~h}$ and dissipation bias of $+4 \mathrm{~h}$, see Table 4). In this case, HARMONIE is able to simulate correctly the fog during the daytime, only with a short surface dissipation that agrees well with the observations (slightly delayed). The model also simulates satisfactorily the fog dissipation process, even the observed temporal dissipation at the surface from 0200 UTC to 0600 UTC. The simulated fog thickness is in accordance with those simulated by WRF, with thicker fog during the first part of the fog and shallower (although thick) during the second part of the fog. The overestimation in fog thickness is greater by HARMONIE than by WRF during the second part of the event.

$T_{2}$ and $q_{2}$ are underestimated by both models (especially by HARMONIE) during most part of the fog event, especially during the first part of the fog (Figure 6a and c). In any case, the evolution of both simulated variables agrees well with the observations. The simulation of $W S_{10}$ (Figure $6 \mathrm{~b}$ ) by WRF agrees well with the observations, but it is systematically overestimated by HARMONIE (mean bias of $+1.29 \mathrm{~m} \mathrm{~s}^{-1}$ ). TKE is correctly simulated by WRF and HARMONIE during the first part of the event and slightly overestimated during most part of the second part (Figure 6d), except for an important $T K E$ decrease simulated by WRF at 1800 UTC of day 22, observed at the same time that the fog dissipation simulated by the model.

\subsection{Event 4. Radiation fog (23 Jan 19:29 - 24 Jan 08:24 UTC)}

\section{Observational description}

Fog event 4 (Figure 7a) is a long $(12.9 \mathrm{~h}$ ) radiation fog with variable thickness (mean of $40 \mathrm{~m}$ ). The fog was only observed at the surface level $(2 \mathrm{~m})$ for more than $4 \mathrm{~h}$ (Figure 7a). At midnight, the fog started growing in the vertical, reaching $100 \mathrm{~m}$ from 0030 UTC to 0130 UTC. The thickness of the fog decreased later and during the rest of the night it oscillated between 2 and $30 \mathrm{~m}$. The fog was dissipated from surface one hour after sunrise (which occurred at 0730 UTC).

As in a pure radiation fog, the fog formation was the result of the decreasing surface temperature, from $13{ }^{\circ} \mathrm{C}$ at $1900 \mathrm{UTC}$ to $8{ }^{\circ} \mathrm{C}$ at $1930 \mathrm{UTC}$ (fog formation) (Figure 8a). The pre-fog surface-based thermal inversion was maintained during the first very-shallow part of the fog (until 0000 UTC). Then the fog grown vertically associated with the turbulent mixing increase (more than one order of magnitude), causing the temperature homogenization at all the levels (increasing at lower levels and decreasing at higher ones, Figure 8a at 0130 UTC). Afterwards, the temperature at different levels diverged and the inversion was formed again, with nighttime surface radiative cooling despite the presence of the fog layer. After the fog dissipation, a quick temperature increase was observed linked to the initiation of the daytime convection. The mean $T_{10}-T_{2}$ during the whole fog was $0.98{ }^{\circ} \mathrm{C}$, showing the characteristics of shallow and not-well mixed fog events, associated with low values of $T K E$ (mean of $0.04 \mathrm{~m}^{2} \mathrm{~s}^{-2}$ ). However, for a short period of time it also showed the characteristics of well-mixed deeper fogs: temperature convergence, $T K E$ up to $0.1 \mathrm{~m}^{2} \mathrm{~s}^{-2}$ and thickness of 
more than $100 \mathrm{~m}$. Despite its mostly shallow character, the mean $W S_{10}$ during this event was the highest observed among all the six analysed events (see Table 3), with $1.80 \mathrm{~m} \mathrm{~s}^{-1}$ of mean and some periods with $W S_{10}$ higher than $2.5 \mathrm{~m} \mathrm{~s}^{-1}$ (at 0100 UTC, Figure 8b), linked to the fog vertical extension. Visibility values (not shown) were extremely low (30-40 m of visibility) when the fog was observed at all the levels (0000 to 0200 UTC). However, values of around $1 \mathrm{~km}$ of visibility were observed during the first part of the very shallow fog and intermediate values in the second part, when the fog presented a thickness of between 30 and $70 \mathrm{~m}$. Therefore, a relation between fog thickness and visibility is clearly observed in this event: the thicker the fog, the more dense it was. $q_{2}$ was continuously decreasing during the event (Figure 8c), with pre-fog values decreasing from 9 to $7 \mathrm{~g} \mathrm{~kg}^{-1}$ in $3 \mathrm{~h}$ and still decreasing during the event to less than $5 \mathrm{~g} \mathrm{~kg}^{-1}$ at the end of the event. The significant increase in $q_{2}$ observed after the fog dissipation suggests that these important variations in atmospheric humidity were due to the condensation/evaporation processes associated with the fog. This event presents the largest variations in $q_{2}$ compared to all the analysed events, and are related to the punctual very low values of visibility reached in some cases. In fact, the increase in $q_{2}$ observed at 0100 UTC was due to enhanced mixing between the surface-fog layer (with less $q_{2}$ ) and air from upper layers (warmer and with relatively high $q_{2}$ ). In these upper layers, the fog was not formed earlier, maintaining their original air humidity values, i.e., without loosing water vapour due to condensation. The mean TKE during the fog was $0.04 \mathrm{~m}^{2} \mathrm{~s}^{-2}$ (Table 3); however, values of up to $0.1 \mathrm{~m}^{2} \mathrm{~s}^{-2}$ were observed between 0000 UTC and 0200 UTC (Figure 8d), favouring the fog vertical extension.

\section{Model skill}

The WRF model was unable to simulate this fog event at all (Figure 7b). However, the model was able to simulate quite correctly the surface variables, including the $T_{2}$ decreasing (Figure 8a, blue thick line), with a slight positive bias of $+0.58{ }^{\circ} \mathrm{C}$ during the fog event (Table 4). $W S_{10}$ was overestimated by the model (bias of $+0.79 \mathrm{~m} \mathrm{~s}^{-1}$ ), but the turbulence was in general quite well simulated (no bias in $T K E$, Figure 8d). The model was even able to simulate the significant $q_{2}$ decrease observed during the whole event (Figure 8c). However, despite the general correct simulation of these key surface variables, the LWC simulated by the model from surface to $300 \mathrm{~m}$ agl remained quite low, with no fog nor mist formation. We think that the modelled decrease in $q_{2}$ should be due to condensation due to its similarity to the observations. However, the relatively high values of wind (this was the event with higher wind speed) in addition to the model overestimation of $+0.79 \mathrm{~m} \mathrm{~s}^{-1}$ could contribute to the unsuccessful formation of fog. Besides, additional issues related with the microphysics scheme could contribute to the inability of the model for the simulation of this event.

The HARMONIE model simulated a fog layer of $200 \mathrm{~m}$ formed as the result of the lowering of low clouds of the previous event 3 (Figure 7c). In fact, the formation mechanism is different from the real one, but the model simulates a fog formed at 2300 UTC (later formation, $+3 \mathrm{~h}$ of bias) and too-late dissipated at $1200 \mathrm{UTC}$ ( $4 \mathrm{~h}$ delayed). Besides, the simulated fog has a thickness of more than $200 \mathrm{~m}$, while a shallower fog was observed with the visibilimeters during most part of the event. The surface-radiative cooling was limited 
in the HARMONIE model (Figure 8a, red thick line) due to the simulation of low clouds during the whole previous day. This leads to a global fog-event overestimation of +2.04 ${ }^{\circ} \mathrm{C}$ (Table 4). $W S_{10}$ and $T K E$ were also clearly overestimated $\left(+1.29{ }^{\circ} \mathrm{C}\right.$ and almost 0.1 $\mathrm{m}^{2} \mathrm{~s}^{-2}$ respectively), as well as $q_{2}$ (almost $1 \mathrm{~g} \mathrm{~kg}^{-1}$ ). That is, the model was able to simulate some fog during the period, but for incorrect reasons and through the incorrect mechanisms, influencing the biases found in surface variables.

\subsection{Event 5. Radiation fog (26 Jan 02:53 - 26 Jan 09:34 UTC)}

\section{Observational description}

This case is a very shallow (thickness of $27 \mathrm{~m}$ ) radiation fog lasting for $6.7 \mathrm{~h}$ (Figure 9a). No fog was observed the day before this event, maybe due to the passage of a front linked to the synoptic trough at the west of the Iberian Peninsula (supplementary figure S1f). However, this event formed even with colder air at higher heights (supplementary figure $\mathrm{S} 1 \mathrm{~g})$. The fog was formed due to the radiative cooling during the first night of day 26 January (Figure 10a); it remains very shallow during a great part of the event, only observed at the first level with observations $(2 \mathrm{~m})$ and extending up to the second level $(30 \mathrm{~m})$ for some moments (Figure 9a). The visibility was lower than $1 \mathrm{~km}$ at 70 and $100 \mathrm{~m}$ levels only during very short periods. The very shallow character of this fog is in accordance with the strong surface-based thermal inversion observed (mean of $1.81{ }^{\circ} \mathrm{C}$ of difference between 10 and $2 \mathrm{~m}$, the maximum inversion in comparison with all the events, Table 3) and with the very low values of $W S_{10}$ and $T K E$ (mean of $1.17 \mathrm{~m} \mathrm{~s}^{-1}$ and $0.03 \mathrm{~m} \mathrm{~s}^{-1}$ respectively, Table 3), being also the lowest mean $W S_{10}$ and $T K E$ values in comparison with the other events.

A thermal inversion was present during the pre-fog period and also during the fog (Figure 10a), with near-surface temperature decreasing during the night despite the fog presence. Some homogenization in the surface temperatures was only observed after sunrise (which occurred at approx. 0730 UTC), associated with the after-sunrise mixing and fog dissipation process. Although $W S_{10}$ and TKE remained low during the event (Figure 10b and d), the fog thickness (Figure 9a) was quite sensitive to sporadic changes in these variables, as observed for example around 0600 UTC. The dissipation of the fog was observed with low values of $W S_{10}$ and was caused by the increase in surface temperature and $T K E$ after sunrise (Figure 10a and c). The $q_{2}$ decrease observed during the pre-fog and first part of the fog event was linked to the condensation process (Figure 10c) while the increase observed in the last stage of the fog event was linked to the mixing of surface levels with air from above, as well as to the droplets evaporation processes associated with the fog dissipation stage.

\section{Model skill}

WRF simulates a radiation fog event firstly formed at the surface about one hour before the real formation (Figure $9 \mathrm{~b}$ ). Then it simulates a fog growing in the vertical up to more than $200 \mathrm{~m}$ and lasting until midday (dissipation $2.5 \mathrm{~h}$ delayed regarding the observations, see Table 4). The model clearly overestimates the fog thickness. With respect to the simulation of surface variables, WRF overestimates $T_{2}$ during most part of the event, with a remarkable 
mean bias of $+3.35{ }^{\circ} \mathrm{C}$ (unable to simulate the surface cooling). It also overestimates $q_{2}$ $\left(+1.35 \mathrm{~g} \mathrm{~kg}^{-1}\right)$. This higher content in surface air humidity allowed the condensation process (fog formation) even with higher simulated values of surface temperature. The model slightly underestimates $W S_{10}$ but overestimates $T K E$, giving rise to exaggerated vertically extended fog.

The HARMONIE model simulates a similar fog as WRF but slightly delayed in time (Figure 9c). This model also overestimates $T_{2}$ and $q_{2}$, with slightly lower (but still significant) bias than WRF $\left(+2.06{ }^{\circ} \mathrm{C}\right.$ and $+0.85 \mathrm{~g} \mathrm{~kg}^{-1}$ respectively, Figure 10a and c). However, in this case, the $W S_{10}$ was overestimated during most part of the event (mean bias of +0.85 $\mathrm{m} \mathrm{s}^{-1}$ ), in contrast to WRF (Figure 10b). Due to the incorrect later dissipation in both models, the temperature is underestimated after the observed fog dissipation stage around 0900 UTC (Figure 10a).

\subsection{Event 6. CBL fog (26 Jan 21:21 - 27 Jan 10:16 UTC)}

\section{Observational description}

This event is a thick (> $100 \mathrm{~m}$ during most part of the period) CBL fog of long duration (13 h, Figure 11a). Additional visibility and long-wave radiation measurements (not shown) from the previous day showed how some low clouds were observed during the day 26 after the morning dissipation of event 5. The fog was formed at 2121 UTC as the result of the lowering of low-cloud bases (Figure 11a). The fog was firstly observed at all the levels with measurements and then converted into a shallow fog for some time around 0000 UTC, to be extended in the vertical up to (at least) $100 \mathrm{~m}$ after 0130 UTC. The final dissipation was observed from the surface well after sunrise and the fog was subsequently transformed into low clouds the following daytime. The mean temperature difference between 10 and 2 $\mathrm{m}$ was low $\left(0.20^{\circ} \mathrm{C}\right.$ ), associated with relatively high values of turbulence (mean $T K E$ of $0.11 \mathrm{~m}^{2} \mathrm{~s}^{-2}$ ), leading to the observed thick fog. This weak stratification fulfils the expected features of deep fog (Román-Cascón et al., 2016b).

As observed in the temperature records (Figure 12a), no surface-based thermal inversion existed before the fog formation and the temperature was well homogenized at all the levels during most part of the event. Only a short period around 0000 UTC showed a temperature decoupling between the surface and higher levels (50 and 85-m) (Figure 12a), associated with the shallow fog observed in that period. $W S_{10}$ was lower than $2 \mathrm{~m} \mathrm{~s}^{-1}$ also during most part of the event except for the period from 0030 UTC to 0200 UTC. Like in CBL-fog event $3, W S_{10}$ decreased during the afternoon allowing the fog formation through a CBL mechanism (Figure 12b). From 0030 UTC to 0200 UTC, $W S_{10}$ increased up to more than $3 \mathrm{~m} \mathrm{~s}^{-1}$ (reaching even values of $5 \mathrm{~m} \mathrm{~s}^{-1}$ ), which caused the fog dissipation at several heights except at the lowest level of $2 \mathrm{~m}$. A similar increase in $W S_{10}$ was observed at the dissipation stage (Figure 12b). Turbulence values remained around $0.04 \mathrm{~m}^{2} \mathrm{~s}^{-2}$ during the whole event, helping the fog vertical extension. However, the excess in turbulence observed around 0200 UTC (0.2-0.4 $\mathrm{m}^{2} \mathrm{~s}^{-2}$, note the high values) did not contribute to the fog vertical extension but to its partial dissipation (Figure 12d). $q_{2}$ behaviour was linked to the temperature evolution, decreasing from 2000 UTC to 0100 UTC (related to the condensation process linked to the 
fog formation Figure 12c). This variable also showed temperature-dependent oscillations during the rest of the event, as expected when saturation values of relative humidity are reached.

\section{Model skill}

WRF simulates basically the continuation of the fog event 5 (Figure 11b and supplementary figure $2 \mathrm{~b}$ ). Thus, it fails in the cloud-base lowering formation mechanism giving rise to this fog. However, the simulated fog has a thickness of 100-200 m which could be in accordance with the observations. The model also simulates a quite correct fog dissipation from the surface ( $+1 \mathrm{~h}$ of bias). The simulation of $T_{2}$ and $W S_{10}$ is acceptable, except during the period around 0000 UTC when the fog was dissipated at higher heights due to the significant observed wind increase (not simulated). TKE was overestimated during the whole fog event except during the period of this commented dissipation.

The HARMONIE model is not able to simulate the fog during this period (Figure 11c and supplementary figure 2c); it only simulates low clouds which were a continuation of event 5 . The simulation of these low clouds damped the observed evening surface cooling (Figure 12a). Thus, the model shows a mean positive $T_{2}$ bias of $+1.41{ }^{\circ} \mathrm{C}$ (Table 4 ). The model also overestimate $W S_{10}$ during most part of the period (Figure 12b) but not $T K E$, which simulation is quite correct (Figure 12d). Regarding $q_{2}$, the model simulates appropriately the range of values, but it is not able to simulate the observed $q_{2}$ decrease from 2000 UTC to 0100 UTC.

\section{Discussion of model results}

From the analysis shown in Section 3, we can state that during this period and in this area, the simulation of radiation fog is more challenging than CBL ones for these two mesoscale models. In order to illustrate the general model skill, Figure 13a shows the models hit rate for the simulation of radiation and CBL fog. This performance indicator is calculated attending to the fog occurrence at each hour (total period of $192 \mathrm{~h}$ ), which is based on visibility measurements (observations) and in LWC output converted to visibility (models). As commented in Section 2, fog is in both cases considered when the visibility is lower than $1000 \mathrm{~m}$ at the lowest level. The radiation-fog hit rate is quite low for WRF $(30 \%$, it missed two events), while it is higher $(75 \%)$ for HARMONIE. The results for CBL fog are different, WRF has a high hit rate of $90 \%$, while the HARMONIE hit-rate only reaches $50 \%$, in part due to the missing of CBL fog event 6 and to biases in the onset and dissipation times of the events. These results show important differences on the model skill depending on the fog-formation mechanism. The model difficulties for the simulation of the radiative cooling at the surface plays a key role to simulate radiation fog. In fact, in some cases, this is caused by the overestimation in duration and thickness of CBL fog (or low clouds) the previous day. That is, if the model simulates an overestimated CBL fog (in thickness and duration), the modelled surface cooling of the next night can be limited by the low-clouds. This effect is observed, for example, for HARMONIE in radiation fog event 1 (Figure 1c and 
Figure 2a) and event 4 (Figure 7c and Figure 8a) and for WRF in event 5 (Figure 9c and Figure 10a).

On the other hand, the total false alarm ratio (hourly basis) was approximately similar for both models ( $29 \%$ for WRF and $28 \%$ for HARMONIE). Note how the evaluation of the false alarm ratio regarding the fog formation mechanism is not possible, since it takes into account periods without observed fog (therefore, the determination of fog type is not possible). Related to this, we have compared the observed and simulated hours of fog (Table 5). At the surface level, the observed visibility was below $1 \mathrm{~km}$ during $60 \mathrm{~h}$ while the models tend to overestimate the fog simulation (82 and $72 \mathrm{~h}$ for WRF and HARMONIE respectively). That is, the models have a tendency to produce too much fog, even despite their inability to simulate some fog events. This result of fog overforecasting agrees with previous findings of works comparing both models (Fernández-González et al., 2019), although they found slightly better skill for HARMONIE than WRF. In any case, the site and the type of the analysed fog events differ from those of this study. Table 5 also shows the number of hours with visibility lower than $1 \mathrm{~km}$ observed at $100 \mathrm{~m}$ agl $(50 \mathrm{~h})$, in comparison with a similar height in the models ( $88 \mathrm{~h}$ for each one). This means that it was more common to observe fog (at $2 \mathrm{~m}$ ) than low visibility (fog or low clouds) at $100 \mathrm{~m}$ agl during the analysed period. However, for the models a tendency exists towards a more frequent simulation of low visibility at around $100 \mathrm{~m}$ than at the surface. This comparison clearly illustrates the tendency of models to vertically overestimate fog, in many cases also observed at around $200 \mathrm{~m}$ agl (see Table 5). This tendency is slightly larger for HARMONIE than for WRF, in accordance with previous studies comparing both models (Steeneveld et al., 2015).

Now we link these results to the biases in fog-related near-surface variables. The models systematically overestimate $T_{2}$ during the radiation fog events (Figure 13b). Despite the better skill of HARMONIE for the simulation of this type of fog, the $T_{2}$ bias is larger $(+1.98$ $\left.{ }^{\circ} \mathrm{C}\right)$ than for WRF $\left(1.26^{\circ} \mathrm{C}\right)$. The positive biases indicate the inability of the models to simulate the real radiative cooling at the surface associated with radiation fog conditions. However, the $T_{2}$ biases are negative and smaller in absolute values during the CBL fog events, which are in general better simulated. The biases of $q_{2}$ (Figure 13c) are linked to those of $T_{2}$; the positive biases during radiation fog indicate the inability of the model to condensate enough water vapour into LWC, due to too high simulated temperatures. On the contrary, both models underestimate $q_{2}$ during CBL fog, linked also to the underestimation of $T_{2}$ for this type of fog (and to an overestimation of LWC and fog thickness). On the other hand, there is a general overestimation of $W S_{10}$ (Figure 13d) for both radiation and CBL fog. The bias is substantially larger for the HARMONIE model than for WRF, as occurs also for $T K E$ (Figure 13e). In any case, the global results for $T K E$ and wind should be analysed with caution, since in the event-by-event analysis we discussed how sudden and unexpected TKE and $W S_{10}$ increases and decreases are typically observed and normally not simulated by the models at the time of occurrence. This is another important weakness of models, since these sudden changes influence the evolution of the fog. 


\section{Summary and conclusions}

A period of 8 consecutive days composed by alternating radiation ( 3 events) and cloudbase lowering (CBL) (3 events) fog has been analysed observationally at the CIBA site in Spain. This period was characterised by relatively calm and stable conditions over the Iberian peninsula. We find a relatively high event-by-event variability of fog characteristics. However, the specific features of radiation and CBL fog are distinguished. The radiation fog events were associated with colder and drier near-surface conditions than CBL ones (2.5 ${ }^{\circ} \mathrm{C}$ versus $6{ }^{\circ} \mathrm{C}$ and $4.9 \mathrm{~g} \mathrm{~kg}^{-1}$ versus $6.3 \mathrm{~g} \mathrm{~kg}^{-1}$ for radiation and CBL fog respectively). The $T K E$ values were significantly lower during radiation $\left(0.04 \mathrm{~m}^{2} \mathrm{~s}^{-2}\right)$ than during $\mathrm{CBL}$ fog $\left(0.11 \mathrm{~m}^{2} \mathrm{~s}^{-2}\right)$, associated with stronger surface-based temperature inversions (mean $T_{10}-T_{2}$ ) in radiation fog $\left(1.14^{\circ} \mathrm{C}\right)$ in comparison with $\mathrm{CBL}$ fog $\left(0.31^{\circ} \mathrm{C}\right)$. These differences in stability affected the differences in mean fog thickness for radiation $(33 \mathrm{~m})$ and CBL fog (normally more than $100 \mathrm{~m})$. However, these differences in $T K E$ were not observed in $W S_{10}$. That is, radiation fog is observed with low values of $T K E$ compared to CBL fog but the same was not observed in $W S_{10}$, which highlights the importance of turbulence in fog evolution. The specific humidity evolution was linked to the temperature changes along the fog event, as expected in conditions of saturated air. The fog thickness (and also the dissipation) showed high sensitivity to small changes in wind speed and turbulence, but particularly in radiation fog.

Subsequently, we have evaluated the fog-forecasting ability of two mesoscale models (WRF and HARMONIE) set up with a similar configuration. Both models exhibited greater difficulties in forecasting radiation fog than CBL fog. For radiation fog, their inability to reach low surface temperature affected the fog simulation, except in some cases when the saturation conditions were well simulated but not the fog, specially for the WRF model. In several cases, the incorrect simulation of previous low-stratus clouds or CBL fog (too thick and/or too extended in time) avoided the real surface radiative cooling needed to simulate radiation fog observed during the next nighttime. That is, under this period with alternating CBL and radiation fog, the models have special difficulties due to this issue, since they normally overestimate the thickness of fog, causing delayed dissipations $(+1.75 \mathrm{~h}$ in WRF and $+5.25 \mathrm{~h}$ in HARMONIE) and too long events.

The hit rate for radiation fog was higher for HARMONIE (75\%) than for WRF (30\%), although only one from three radiation fog events was simulated correctly by both models. For CBL fog, the models had fewer problems, with a hit rate of $90 \%$ for WRF and $50 \%$ for HARMONIE. The event which was better simulated by both models was the long-lasting and persistent CBL fog event 3, which was the longest and most persistent one. Shallow and shorter fog events were more challenging for the models. Regarding the simulation of key surface variables during the fog events, the WRF model presented smaller biases than HARMONIE, although in some cases this did not improve the simulation of fog. Moreover, in some radiation-fog events the WRF model showed an appropriate simulation of surface variables (temperature, specific humidity, wind and turbulence) but no fog at all.

This work shows how NWP models still need to be improved to reach acceptable fog forecasting. In particular, they need to avoid the exaggerated vertical extension and duration 
of CBL fog (and also low clouds) that influence the surface cooling needed to simulate the formation of radiation fog events formed during the next night. They also need to take into account processes (which are probably sub-grid scale processes or mesoscale phenomena not well simulated) that can generate turbulence or increase the wind speed during the night, since the fog (especially radiation fog) is highly influenced by these changes that are normally not simulated by the models. In any case, sensitivity analyses of different model schemes and parameterizations (as for example done in Wilson and Fovell (2018)) can also help providing us more insight about the specific changes needed in models to simulate some of the most difficult cases, like the shallow radiation fog events.

\section{Acknowledgements}

This research has been funded by two Spanish National Projects [Ref. CGL2012-37416C04-02 (MINECO/FEDER) and Ref. CGL2015-65627-C3-3-R (MINECO/FEDER)]. Jon A. Arrillaga is supported by the Predoctoral Training Program for No-Doctor Researchers of the Department of Education, Language Policy and Culture of the Basque Government (PRE_2017_2_0069, MOD = B). Thanks to ECMWF for providing the data for the initialization of the models. We thank www.meteociel.com and NCEP for the reanalysis maps shown in the supplementary material. 


\section{References}

\section{References}

Azevedo, J., Morgan, D., 1974. Fog precipitation in coastal california forests. Ecology 55 (5), $1135-1141$.

Bari, D., Bergot, T., El Khlifi, M., 2015. Numerical study of a coastal fog event over casablanca, morocco. Quart. J. Roy. Meteor. Soc. 141 (690), 1894-1905.

Bartok, J., Bott, A., Gera, M., 2012. Fog prediction for road traffic safety in a coastal desert region. Boundary-Layer Meteorol. 145 (3), 485-506.

Bengtsson, L., Andrae, U., Aspelien, T., Batrak, Y., Calvo, J., de Rooy, W., Gleeson, E., Hansen-Sass, B., Homleid, M., Hortal, M., et al., 2017. The harmonie-arome model configuration in the aladin-hirlam nwp system. Mon. Weather Rev. 145 (5), 1919-1935.

Bergot, T., apr 2013. Small-scale structure of radiation fog: a large-eddy simulation study. Q. J. R. Meteorol. Soc. 139 (673), 1099-1112.

URL http://doi.wiley.com/10.1002/qj.2051

Bergot, T., Guedalia, D., 1994. Numerical forecasting of radiation fog. part i: Numerical model and sensitivity tests. Mon. Weather Rev. 122 (6), 1218-1230.

Bergot, T., Terradellas, E., Cuxart, J., Mira, A., Liechti, O., Mueller, M., Nielsen, N. W., 2007. Intercomparison of single-column numerical models for the prediction of radiation fog. Journal of Applied Meteorology and Climatology 46 (4), 504-521.

Boutle, I., Finnenkoetter, A., Lock, A., Wells, H., 2016. The london model: forecasting fog at $333 \mathrm{~m}$ resolution. Quart. J. Roy. Meteor. Soc. 142 (694), 360-371.

Chaouch, N., Temimi, M., Weston, M., Ghedira, H., may 2017. Sensitivity of the meteorological model wrf-arw to planetary boundary layer schemes during fog conditions in a coastal arid region. Atmos. Res. $187,106-127$.

Cornejo-Bueno, L., Casanova-Mateo, C., Sanz-Justo, J., Cerro-Prada, E., Salcedo-Sanz, S., 2017. Efficient prediction of low-visibility events at airports using machine-learning regression. Boundary-layer meteorol. 165 (2), 349-370.

Cuxart, J., Yagüe, C., Morales, G., Terradellas, E., Orbe, J., Calvo, J., Fernández, A., Soler, M., Infante, C., Buenestado, P., et al., 2000. Stable atmospheric boundary-layer experiment in spain (sables 98): a report. Boundary Layer Meteorol. 96 (3), 337-370.

Dawson, T. E., 1998. Fog in the california redwood forest: ecosystem inputs and use by plants. Oecologia 117 (4), 476-485.

Dupont, J.-C., Haeffelin, M., Protat, A., Bouniol, D., Boyouk, N., Morille, Y., 2012. Stratus-fog formation and dissipation: a 6-day case study. Boundary Layer Meteorol. 143 (1), 207-225.

Dupont, J.-C., Haeffelin, M., Wærsted, E., Delanoe, J., Renard, J.-B., Preissler, J., O'dowd, C., 2018. Evaluation of fog and low stratus cloud microphysical properties derived from in situ sensor, cloud radar and syrsoc algorithm. Atmosphere 9 (5), 169.

Duynkerke, P. G., 1999. Turbulence, radiation and fog in dutch stable boundary layers. Boundary Layer Meteorol. 90 (3), 447-477.

Duynkerke, P. G., Hignett, P., 1993. Simulation of diurnal variation in a stratocumulus-capped marine boundary layer during fire. Mon. Weather Rev. 121 (12), 3291-3300.

Fabbian, D., de Dear, R., Lellyett, S., 2007. Application of artificial neural network forecasts to predict fog at canberra international airport. Weather Forecasting 22 (2), 372-381.

Fernández-González, S., Bolgiani, P., Fernández-Villares, J., González, P., García-Gil, A., Suárez, J. C., Merino, A., 2019. Forecasting of poor visibility episodes in the vicinity of tenerife norte airport. Atm. Res. 223, 49-59.

Fu, G., Li, P., Crompton, J. G., Guo, J., Gao, S., Zhang, S., 2010. An observational and modeling study of a sea fog event over the yellow sea on 1 august 2003. Meteorol. Atmos. Phys. 107 (3-4), 149-159.

Funk, J., 1962. Radiative flux divergence in radiation fog. Quart. J. Roy. Meteor. Soc. 88 (377), $233-249$.

Goodman, J., 1977. The microstructure of california coastal fog and stratus. J. Appl. Meteorol. 16 (10), 1056-1067. 
Guijo-Rubio, D., Gutiérrez, P., Casanova-Mateo, C., Sanz-Justo, J., Salcedo-Sanz, S., Hervás-Martínez, C., 2018. Prediction of low-visibility events due to fog using ordinal classification. Atmos. Res. 214, 64-73.

Gultepe, I., Tardif, R., Michaelides, S., Cermak, J., Bott, A., Bendix, J., Müller, M. D., Pagowski, M., Hansen, B., Ellrod, G., et al., 2007. Fog research: A review of past achievements and future perspectives. Pure Appl. Geophys. 164 (6-7), 1121-1159.

Hang, C., Nadeau, D., Gultepe, I., Hoch, S., Román-Cascón, C., Pryor, K., Fernando, H., Creegan, E., Leo, L., Silver, Z., et al., 2016. A case study of the mechanisms modulating the evolution of valley fog. Pure Appl. Geophys. 173 (9), 3011-3030.

Hu, H., Zhang, Q., Xie, B., Ying, Y., Zhang, J., Wang, X., 2014. Predictability of an advection fog event over north china. part i: Sensitivity to initial condition differences. Mon. Weather Rev. 142 (5), 1803-1822.

Hyvärinen, O., Julkunen, J., Nietosvaara, V., may 2007. Climatological Tools for Low Visibility Forecasting. Pure Appl. Geophys. 164 (6-7), 1383-1396. URL http://link.springer.com/10.1007/s00024-007-0224-5

Koračin, D., Lewis, J., Thompson, W. T., Dorman, C. E., Businger, J. A., 2001. Transition of stratus into fog along the california coast: Observations and modeling. J. Atmos. Sci. 58 (13), 1714-1731.

Kunkel, B. A., 1984. Parameterization of droplet terminal velocity and extinction coefficient in fog models. J. Clim. Appl. Meteorol. 23 (1), 34-41.

McCabe, A., Swinbank, R., Tennant, W., Lock, A., 2016. Representing model error in the met office convection permitting ensemble prediction system.

Mohan, M., Payra, S., apr 2009. Influence of aerosol spectrum and air pollutants on fog formation in urban environment of megacity Delhi, India. Environ. Monit. Assess. 151 (1-4), 265-77. URL http://www.ncbi.nlm.nih.gov/pubmed/18379890

Müller, M. D., Masbou, M., Bott, A., 2010. Three-dimensional fog forecasting in complex terrain. Quart. J. Roy. Meteor. Soc. 136 (653), 2189-2202.

Oliver, D., Lewellen, W., Williamson, G., 1978. The interaction between turbulent and radiative transport in the development of fog and low-level stratus. J. Atmos. Sci. 35 (2), 301-316.

Philip, A., Bergot, T., Bouteloup, Y., Bouyssel, F., 2016. The impact of vertical resolution on fog forecasting in the kilometric-scale model arome: A case study and statistics. Weather Forecasting 31 (5), 1655-1671.

Price, J., Lane, S., Boutle, I., Smith, D., Bergot, T., Lac, C., Duconge, L., McGregor, J., Kerr-Munslow, A., Pickering, M., et al., 2018. Lanfex: A field and modeling study to improve our understanding and forecasting of radiation fog. Bull. Amer. Meteor. Soc. 99 (10), 2061-2077.

Roco, F. L., de Arellano, J. V.-G., Pedruzo-Bagazgoitia, X., 2018. Characterizing the influence of the marine stratocumulus cloud on the land fog at the atacama desert. Atmos. Res. 214, 109-120.

Román-Cascón, C., Steeneveld, G., Yagüe, C., Sastre, M., Arrillaga, J., Maqueda, G., 2016a. Forecasting radiation fog at climatologically contrasting sites: evaluation of statistical methods and wrf. Quart. J. Roy. Meteor. Soc. 142 (695), 1048-1063.

Román-Cascón, C., Yagüe, C., Sastre, M., Maqueda, G., Salamanca, F., Viana, S., 2012. Observations and wrf simulations of fog events at the spanish northern plateau. Adv. Sci. Res. 8 (1), 11-18.

Román-Cascón, C., Yagüe, C., Steeneveld, G.-J., Sastre, M., Arrillaga, J. A., Maqueda, G., 2016b. Estimating fog-top height through near-surface micrometeorological measurements. Atm. Res. 170, 76-86.

Shanyengana, E., Henschel, J., Seely, M., Sanderson, R., 2002. Exploring fog as a supplementary water source in namibia. Atmos. Res. 64 (1-4), 251-259.

Skamarock, W. C., Klemp, J. B., Dudhia, J., Gill, D. O., Barker, D. M., Wang, W., Powers, J. G., 2005. A description of the advanced research wrf version 2. Tech. rep., National Center For Atmospheric Research Boulder Co Mesoscale and Microscale ....

Steeneveld, G., Ronda, R., Holtslag, A., 2015. The challenge of forecasting the onset and development of radiation fog using mesoscale atmospheric models. Boundary Layer Meteorol. 154 (2), 265-289.

Tanaka, H., Honma, S., Nishi, M., Igarashi, T., Teramoto, S., Nishio, F., Abe, S., 1998. Acid fog and hospital visits for asthma: an epidemiological study. Eur. Respir. J. 11 (6), 1301-1306.

Tardif, R., Rasmussen, R. M., aug 2007. Event-based climatology and typology of fog in the New York City region. J. Appl. Meteorol. Clim. 46 (8), 1141-1168. 
URL http://journals.ametsoc.org/doi/abs/10.1175/JAM2516.1

Teixeira, J., 1999. Simulation of fog with the ecmwf prognostic cloud scheme. Q. J. R. Meteorol. Soc. 125 (554), 529-552.

Terradellas, E., Ferreres, E., Soler, M., 2008. Analysis of turbulence in fog episodes. Adv. Sci. Res. 2, 31-34.

Van der Velde, I., Steeneveld, G. J., Wichers Schreur, B., Holtslag, A. A. M., 2010. Modeling and forecasting the onset and duration of severe radiation fog under frost conditions. Mon. Weather Rev. 138 (11), 42374253.

Van Schalkwyk, L., Dyson, L. L., 2013. Climatological characteristics of fog at cape town international airport. Weather Forecasting 28 (3), 631-646.

Wilson, T. H., Fovell, R. G., 2018. Modeling the evolution and life cycle of radiative cold pools and fog. Weather Forecasting 33 (1), 203-220.

Zhou, B., Du, J., Gultepe, I., Dimego, G., 2012. Forecast of low visibility and fog from ncep: Current status and efforts. Pure Appl. Geophys. 169 (5-6), 895-909.

Zhou, B., Ferrier, B. S., 2008. Asymptotic analysis of equilibrium in radiation fog. J. Appl. Meteorol. Clim. 47 (6), 1704-1722. 
Table 1: Observational measurements used, height(s) and type of sensor.

\begin{tabular}{ccc} 
Variable & Height $(\mathbf{m})$ & Instrument \\
\hline Visibility & $2,30,70,100$ & Biral SWS 100 \\
Temperature & $1.5,5,10,50,85$ & Theodor Friedrichs 3032.02 \\
Specific humidity & 1.5 & Theodor Friedrichs 3032.02 \\
Wind speed & 10 & Theodor Friedrichs 4035.01 \\
Turbulent kinetic energy (TKE) & 10 & Sonic anemometer METEK-USA-1
\end{tabular}

Table 2: Information about models configuration.

\begin{tabular}{c|cc} 
& WRF-ARW & HARMONIE-AROME \\
\hline Horizontal resolution & $2.5 \mathrm{~km}$ & $2.5 \mathrm{~km}$ \\
Model domain & $300 \times 300$ points & $300 \mathrm{x} 300$ points \\
Initial and boundary conditions & ECMWF operational analysis & ECMWF operational analysis \\
PBL scheme & TKE-I scheme MYNN & TKE-I CBR \\
LSM & Noah & SURFEX \\
Microphysics & WDM6 6 & ICE3 \\
Number of vertical levels & 61 & 65 \\
Time step & $60 \mathrm{~s}$ & $60 \mathrm{~s}$ \\
Leading time & $24 \mathrm{~h}$ & $24 \mathrm{~h}$
\end{tabular}


Table 3: Main characteristics from the observational analysis of fog events. The represented values for the different variables (2-m temperature, 2-m specific humidity, 10-m wind speed, turbulent kinetic energy, temperature difference between the levels of 10 and $2 \mathrm{~m}$ agl $\left(T_{10}-T_{2}\right)$ and fog thickness) correspond to the mean calculated from the fog onset to its dissipation. Times are in UTC.

\begin{tabular}{|c|c|c|c|c|c|c|c|c|c|c|}
\hline Event & $\begin{array}{l}\text { Fog } \\
\text { type }\end{array}$ & $\begin{array}{c}\text { Onset } \\
\text { time }\end{array}$ & $\begin{array}{c}\text { Dissipation } \\
\text { time }\end{array}$ & $\begin{array}{c}\text { Duration } \\
\text { (h) }\end{array}$ & $\begin{array}{c}T_{2} \\
\left({ }^{\circ} \mathrm{C}\right)\end{array}$ & $\begin{array}{c}q_{2} \\
\left(\mathrm{~g} \mathrm{~kg}^{-1}\right)\end{array}$ & $\begin{array}{l}W S_{10} \\
\left(\mathrm{~m} \mathrm{~s}^{-1}\right)\end{array}$ & $\begin{array}{c}T K E \\
\left(\mathrm{~m}^{2} \mathrm{~s}^{-2}\right)\end{array}$ & $\begin{array}{c}T_{10}-T_{2} \\
\left({ }^{\circ} \mathrm{C}\right)\end{array}$ & $\begin{array}{c}\text { Thickness } \\
(\mathrm{m})\end{array}$ \\
\hline 1 & $\operatorname{Rad}$ & $\begin{array}{c}\text { Day } 20 \\
00: 41\end{array}$ & $\begin{array}{c}\text { Day } 20 \\
04: 23\end{array}$ & $\begin{array}{c}3.7 \\
\text { (short) }\end{array}$ & -0.84 & 3.76 & 1.34 & 0.05 & 0.63 & 34 \\
\hline 2 & CBL & $\begin{array}{c}\text { Day } 20 \\
23: 09\end{array}$ & $\begin{array}{c}\text { Day } 21 \\
01: 09\end{array}$ & $\begin{array}{c}2.0 \\
\text { (short) }\end{array}$ & 5.32 & 5.91 & 1.73 & 0.14 & 0.24 & $>100$ \\
\hline 3 & $\mathrm{CBL}$ & $\begin{array}{c}\text { Day } 21 \\
18: 32\end{array}$ & $\begin{array}{c}\text { Day } 23 \\
10: 47\end{array}$ & $\begin{array}{c}40.2 \\
\text { (persistent) }\end{array}$ & 8.76 & 7.54 & 1.32 & 0.07 & 0.50 & Variable \\
\hline 4 & $\operatorname{Rad}$ & $\begin{array}{c}\text { Day } 23 \\
19: 29\end{array}$ & $\begin{array}{c}\text { Day } 24 \\
08: 24\end{array}$ & $\begin{array}{l}12.9 \\
\text { (long) }\end{array}$ & 5.93 & 6.18 & 1.80 & 0.04 & 0.98 & 40 \\
\hline 5 & $\operatorname{Rad}$ & $\begin{array}{c}\text { Day } 26 \\
02: 53\end{array}$ & $\begin{array}{c}\text { Day } 26 \\
09: 34\end{array}$ & $\begin{array}{c}6.7 \\
\text { (intermediate) }\end{array}$ & 2.51 & 4.83 & 1.17 & 0.03 & 1.81 & 27 \\
\hline 6 & $\mathrm{CBL}$ & $\begin{array}{c}\text { Day } 26 \\
21: 21\end{array}$ & $\begin{array}{c}\text { Day } 27 \\
10: 16\end{array}$ & $\begin{array}{c}13 \\
\text { (long) }\end{array}$ & 3.90 & 5.38 & 1.52 & 0.11 & 0.20 & Variable \\
\hline RAD & // & // & // & 7.8 & 2.53 & 4.92 & 1.44 & 0.04 & 1.14 & 33 \\
\hline CBL & // & // & // & 18.4 & 5.99 & 6.27 & 1.52 & 0.11 & 0.31 & $\begin{array}{l}\text { Variable / } \\
>100\end{array}$ \\
\hline
\end{tabular}


Table 4: Mean WRF and HARMONIE (HAR) model bias for different variables analysed for each fog event (strictly the fog period defined in Table 3). The mean bias for all the events is included in the last column, as well as the mean of event-biases in absolute values (in parenthesis). ${ }^{*}$ indicates that the fog was simulated following an incorrect formation mechanism.

\begin{tabular}{c|cccccc|c} 
& $\begin{array}{c}\text { Event 1 } \\
\text { Rad }\end{array}$ & $\begin{array}{c}\text { Event 2 } \\
\text { CBL }\end{array}$ & $\begin{array}{c}\text { Event 3 } \\
\text { CBL }\end{array}$ & $\begin{array}{c}\text { Event 4 } \\
\text { Rad }\end{array}$ & $\begin{array}{c}\text { Event 5 } \\
\text { Rad }\end{array}$ & $\begin{array}{c}\text { Event 6 } \\
\text { CBL }\end{array}$ & $\begin{array}{c}\text { All } \\
\text { (abs) }\end{array}$ \\
\hline Fog & & & & & & & \\
WRF & No & Yes & Yes & No & Yes & Yes & $4 / 6$ \\
HAR & No & Yes & Yes & Yes* & Yes & No & $4 / 6$ \\
\hline Onset $(\mathbf{h})$ & & & & & & & \\
WRF bias & $/ /$ & -8 & -1 & $/ /$ & -1 & -6 & $-4(4)$ \\
HAR bias & $/ /$ & -5 & +4 & +3 & +1 & $/ /$ & $+0.75(3.25)$ \\
\hline Dissipation $(\mathbf{h})$ & & & & & & & \\
WRF bias & $/ /$ & +2 & +1 & $/ /$ & +3 & +1 & $+1.75(1.75)$ \\
HAR bias & $/ /$ & +10 & +4 & +4 & +3 & $/ /$ & $+5.25(5.25)$ \\
\hline$T_{2}\left({ }^{\circ} \mathbf{C}\right)$ & & & & & & & \\
WRF bias & $-0,16$ & $-2,20$ & $-0,76$ & $+0,58$ & $+3,35$ & $-0,67$ & $+0,02(1.28)$ \\
HAR bias & $+1,84$ & $-3,18$ & $-1,26$ & $+2,04$ & $+2,06$ & $+1,41$ & $+0,49(1.97)$ \\
\hline$q_{2}\left(\mathbf{g ~ k g ~}^{-\mathbf{1}}\right)$ & & & & & & & \\
WRF bias & $+0,09$ & $-0,76$ & $-0,33$ & $+0,09$ & $+1,35$ & $-0,26$ & $+0,03(0.48)$ \\
HAR bias & $+0,63$ & $-1,09$ & $-0,59$ & $+0,95$ & $+0,85$ & $+0,40$ & $+0,19(0.75)$ \\
\hline$W S_{10}\left(\mathbf{m ~ s}^{-\mathbf{1}}\right)$ & & & & & & & \\
WRF bias & $+0,16$ & $-0,04$ & $+0,50$ & $+0,79$ & $-0,23$ & $-0,18$ & $+0,17(0.32)$ \\
HAR bias & $+1,76$ & $-0,74$ & $+1,29$ & $+1,05$ & $+0,85$ & $+0,66$ & $+0,81(1.06)$ \\
\hline$T K E\left(\mathbf{m}^{\mathbf{2}} \mathbf{s}^{\mathbf{- 2}}\right)$ & & & & & & & \\
WRF bias & $-0,01$ & $-0,16$ & $+0,03$ & $+0,00$ & $+0,09$ & $+0,03$ & $+0,00(0.05)$ \\
HAR bias & $+0,09$ & $-0,28$ & $+0,02$ & $+0,09$ & $+0,04$ & $-0,07$ & $-0,02(0.10)$ \\
\hline
\end{tabular}

Table 5: Number of hours with visibility lower than $1 \mathrm{~km}$ from a total of $192 \mathrm{~h}$ analysed at three different levels. Observation levels are 2 and $100 \mathrm{~m}$ (no visibilimeter above). WRF levels are 13, 113 and $204 \mathrm{~m}$. HARMONIE levels are 13, 113 and $220 \mathrm{~m}$. Modelled and observed hours differences are also included with percentages of overestimation between brackets. The $200-\mathrm{m}$ level is included to show the model tendency to extend the fog in the vertical.

\begin{tabular}{c|lll} 
& \multicolumn{4}{|c}{ Hours with vis $<\mathbf{1 ~ k m}$} \\
& lowest level & $\sim \mathbf{1 0 0} \mathbf{~ m}$ & $\sim \mathbf{2 0 0} \mathbf{~ m}$ \\
\hline OBS & $60 \mathrm{~h}$ & $50 \mathrm{~h}$ & $/ /$ \\
WRF & $82 \mathrm{~h}(+36 \%)$ & $88 \mathrm{~h}(+76 \%)$ & $77 \mathrm{~h}$ \\
HAR & $72 \mathrm{~h}(+20 \%)$ & $88 \mathrm{~h}(+76 \%)$ & $87 \mathrm{~h}$
\end{tabular}



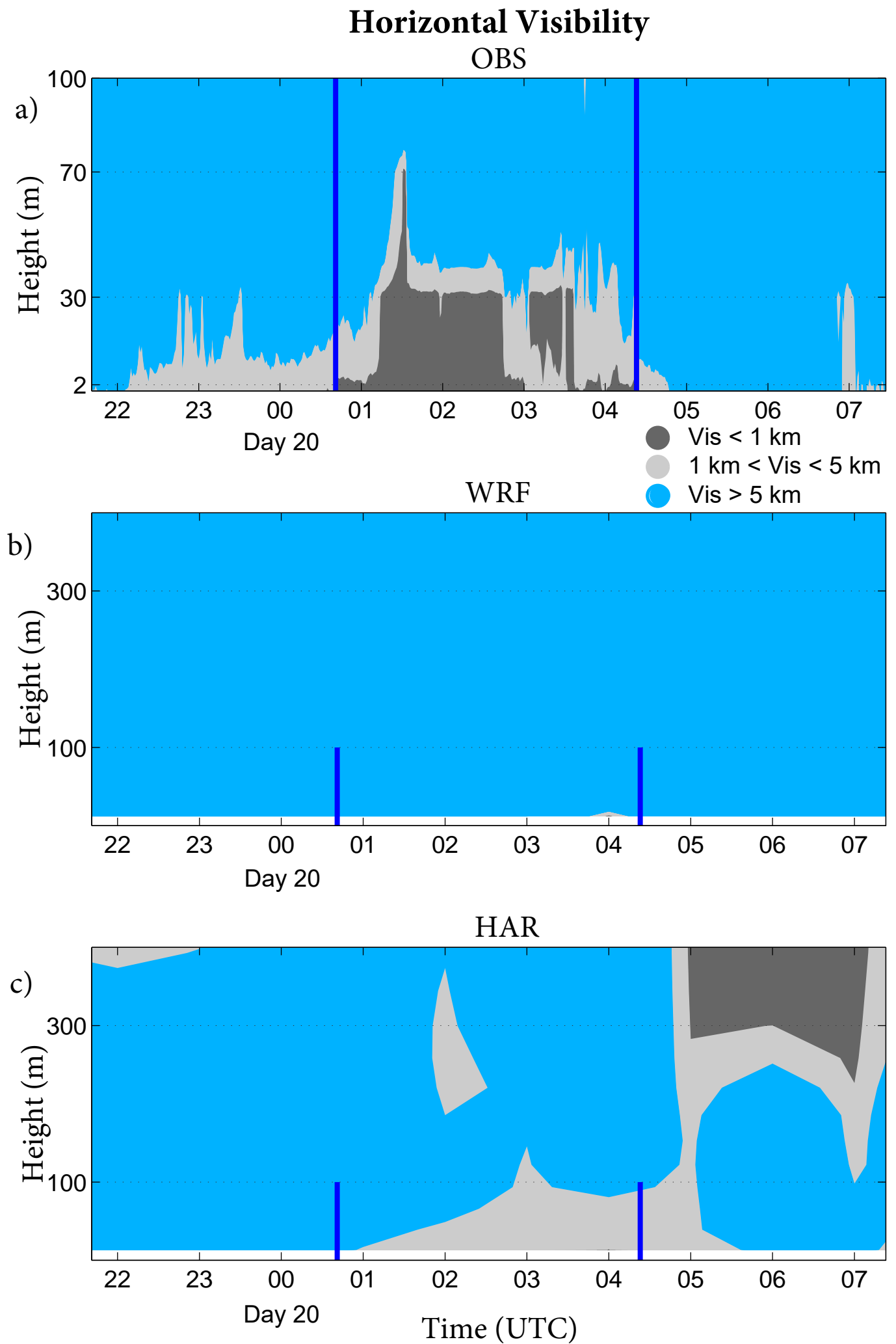

Figure 1: a) Fog observed at the CIBA site during event 1, from 20/01 at 0041 UTC to 20/01 at 0423 UTC. Fog is indicated with dark grey colours (vis $<1 \mathrm{~km}$ ), mist with light grey colours $(1 \mathrm{~km}<$ vis $<5 \mathrm{~km})$ and visibility $>5 \mathrm{~km}$ with blue. Horizontal dotted lines indicate the heights with visibilimeters $(2,30,70$ and $100 \mathrm{~m})$. Plotted data between these data are interpolated linearly. Vertical blue lines indicate the initial and end of the fog event. b) Corresponding simulation by the WRF model up to $400 \mathrm{~m}$. Blue vertical lines indicate the foggy period from figure a, only up to $109 \mathrm{~m}$ because of the lack of observational data above. c) Idem for HARMONIE model. 
a)
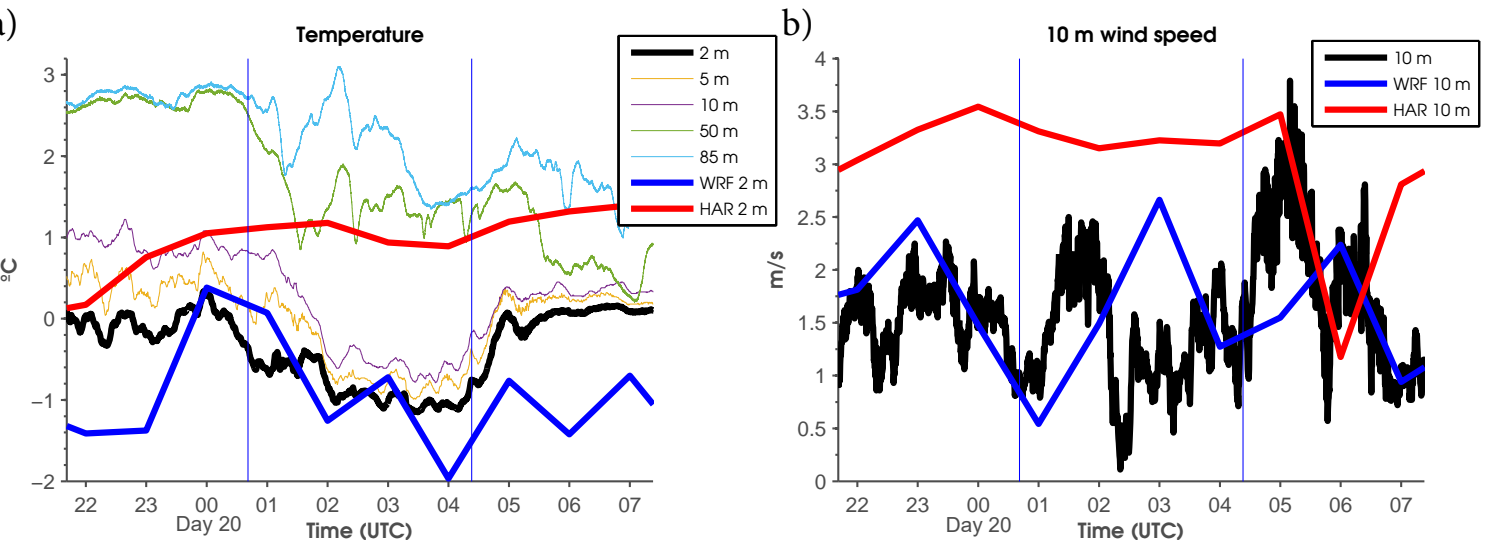

c)
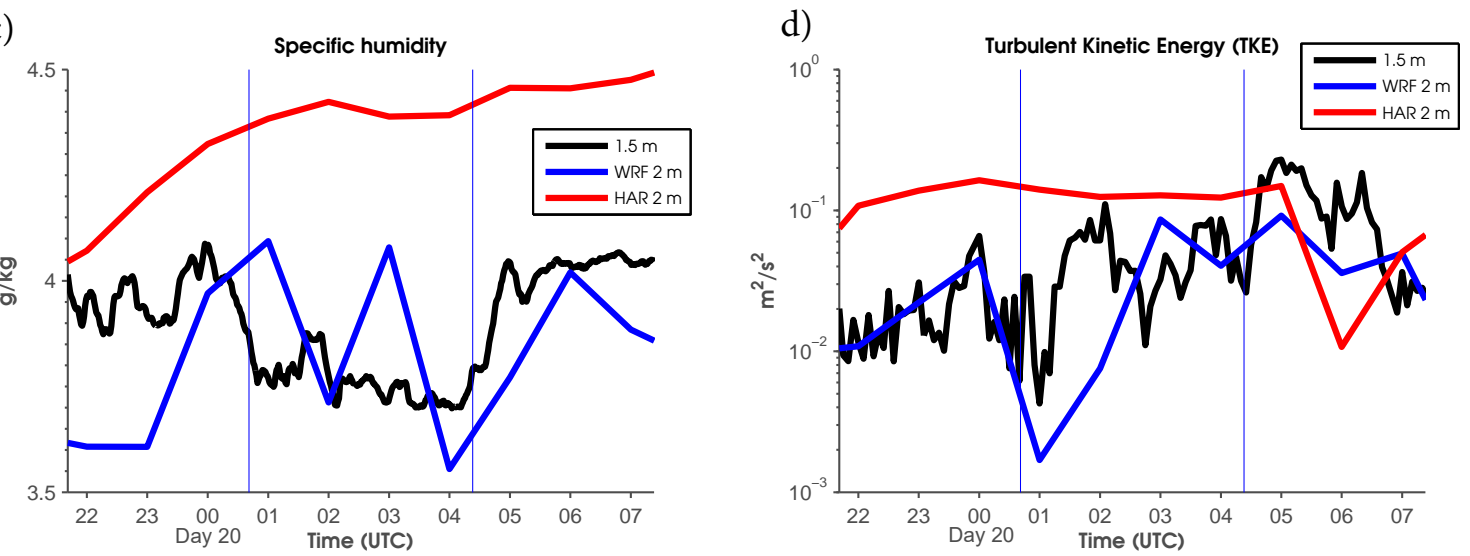

Figure 2: Fog event 1. a) Observed (thick black line) and simulated temperature $\left({ }^{\circ} \mathrm{C}\right)$ at $2 \mathrm{~m}(\mathrm{WRF}$, blue line; HARMONIE, red line). Observed temperatures at $5 \mathrm{~m}$ (yellow), $10 \mathrm{~m}$ (purple), $50 \mathrm{~m}$ (green) and $85 \mathrm{~m}$ (light blue) are included in order to show surface-based temperature inversions and temperature convergence. b) Idem for $10-\mathrm{m}$ wind speed $\left(\mathrm{m} \mathrm{s}^{-1}\right)$. c) Idem for 1.5 -m specific humidity $\left(\mathrm{g} \mathrm{kg}^{-1}\right)(2 \mathrm{~m} \mathrm{for}$ the models). d) Idem for 1.5-m TKE $\left(\mathrm{m}^{2} \mathrm{~s}^{-2}\right)$ (2 $\mathrm{m}$ for the models). Vertical blue lines indicate strictly the fog period. 

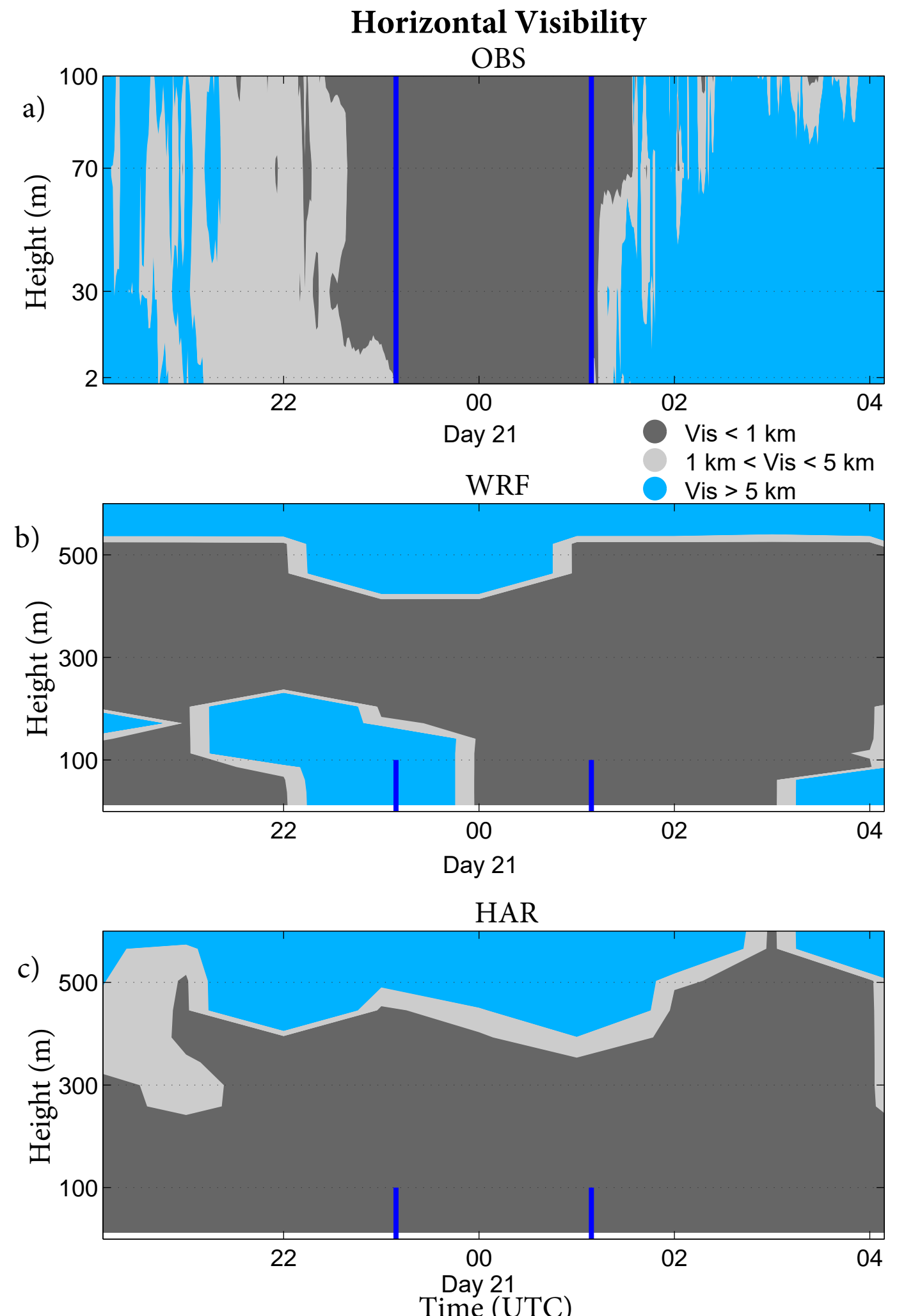

Figure 3: Idem than Figure 1 but for event 2, from 20/01 at 2309 UTC to 21/01 at 0109 UTC. 
a)

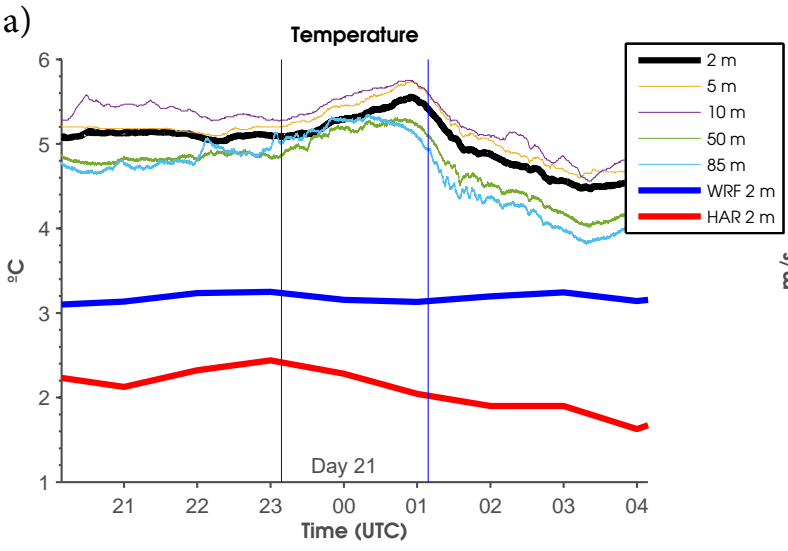

c)

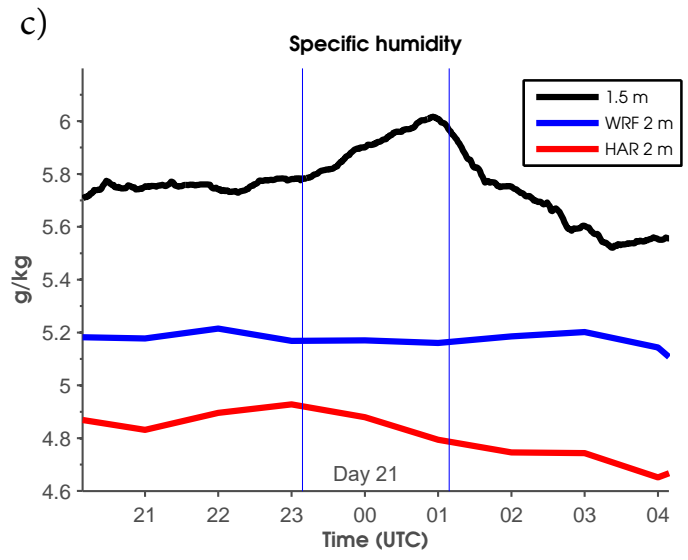

b)
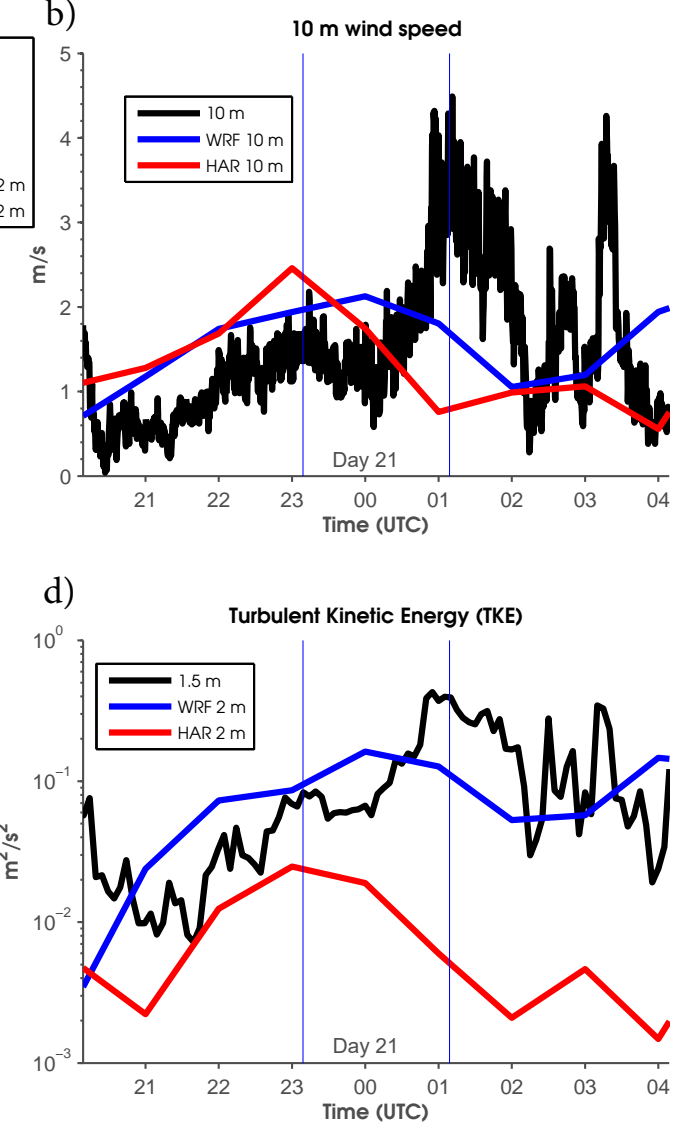

Figure 4: Idem than Figure 2 but for event 2, from 20/01 at 2309 UTC to 21/01 at 0109 UTC. 
Horizontal Visibility

OBS
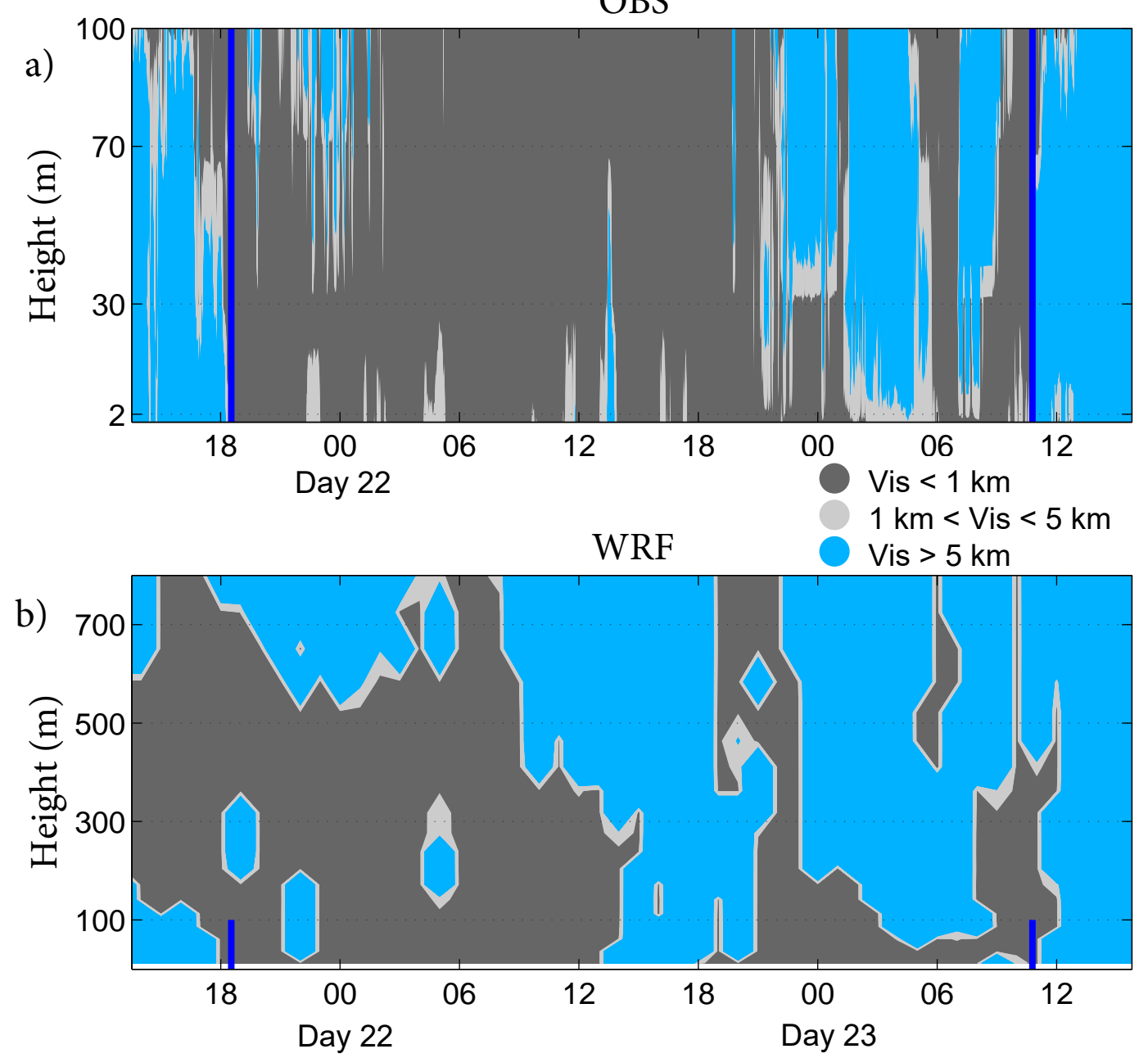

HAR

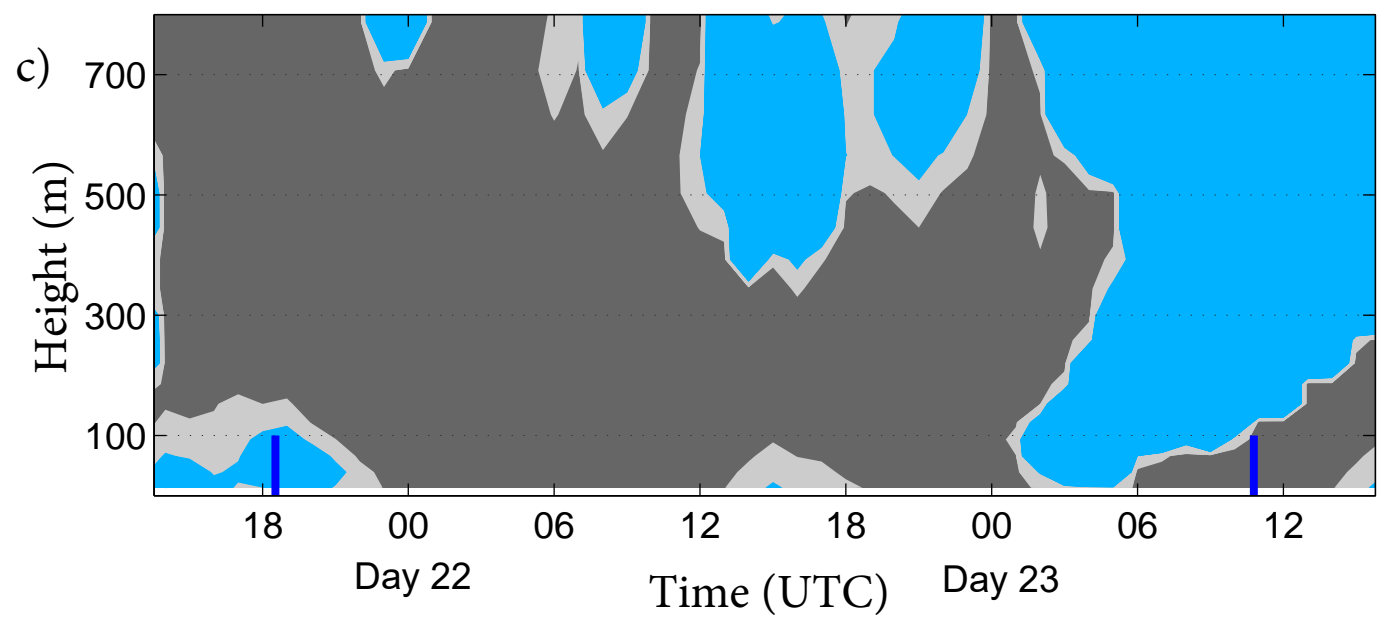

Figure 5: Idem than Figure 1 but for event 3, from 21/01 at 1832 UTC to 23/01 at 1047 UTC. 
a)

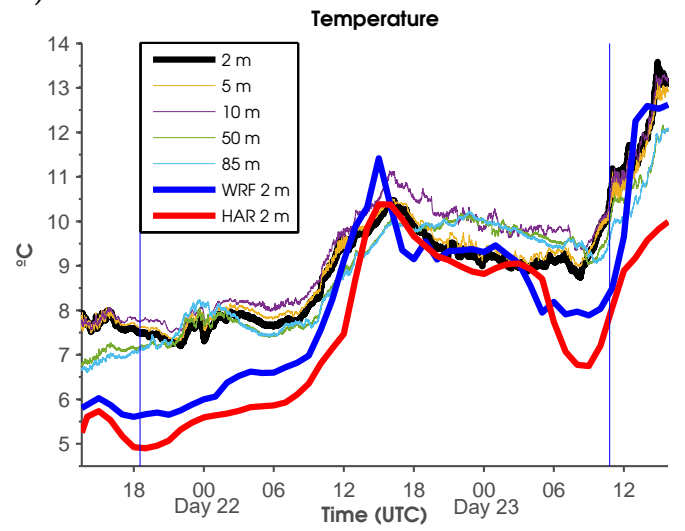

c)

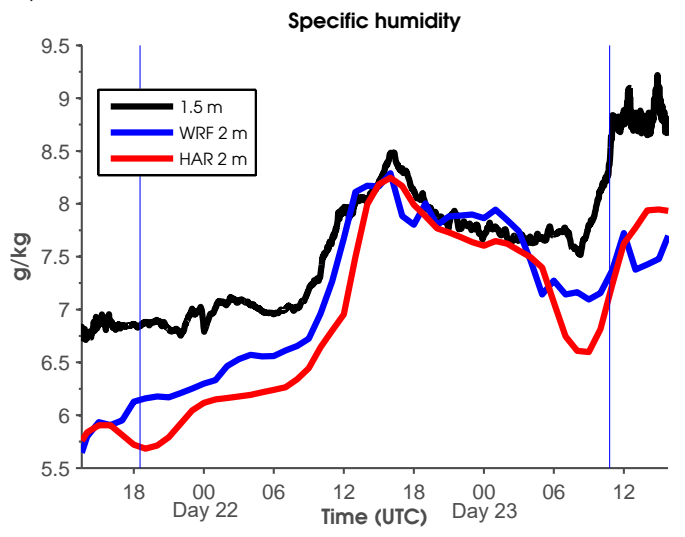

b)

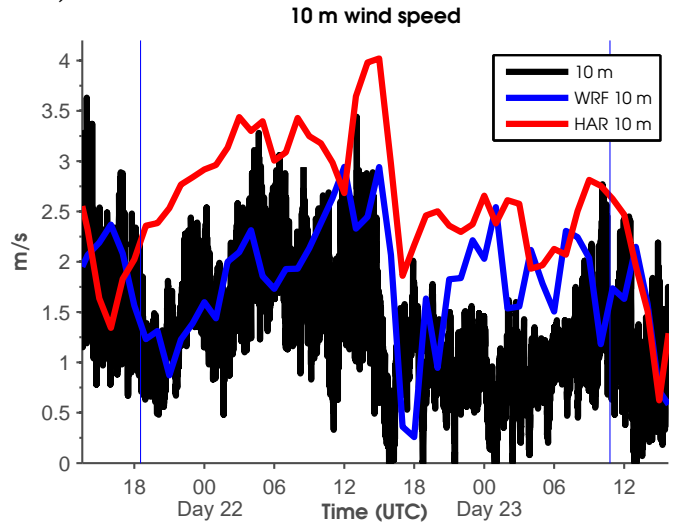

d)

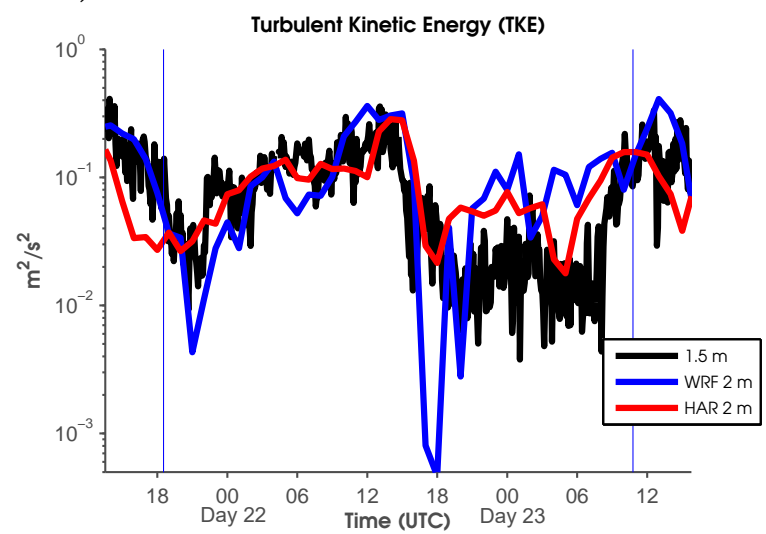

Figure 6: Idem than Figure 2 but for event 3, from 21/01 at 1832 UTC to 23/01 at 1047 UTC. 


\section{Horizontal Visibility}

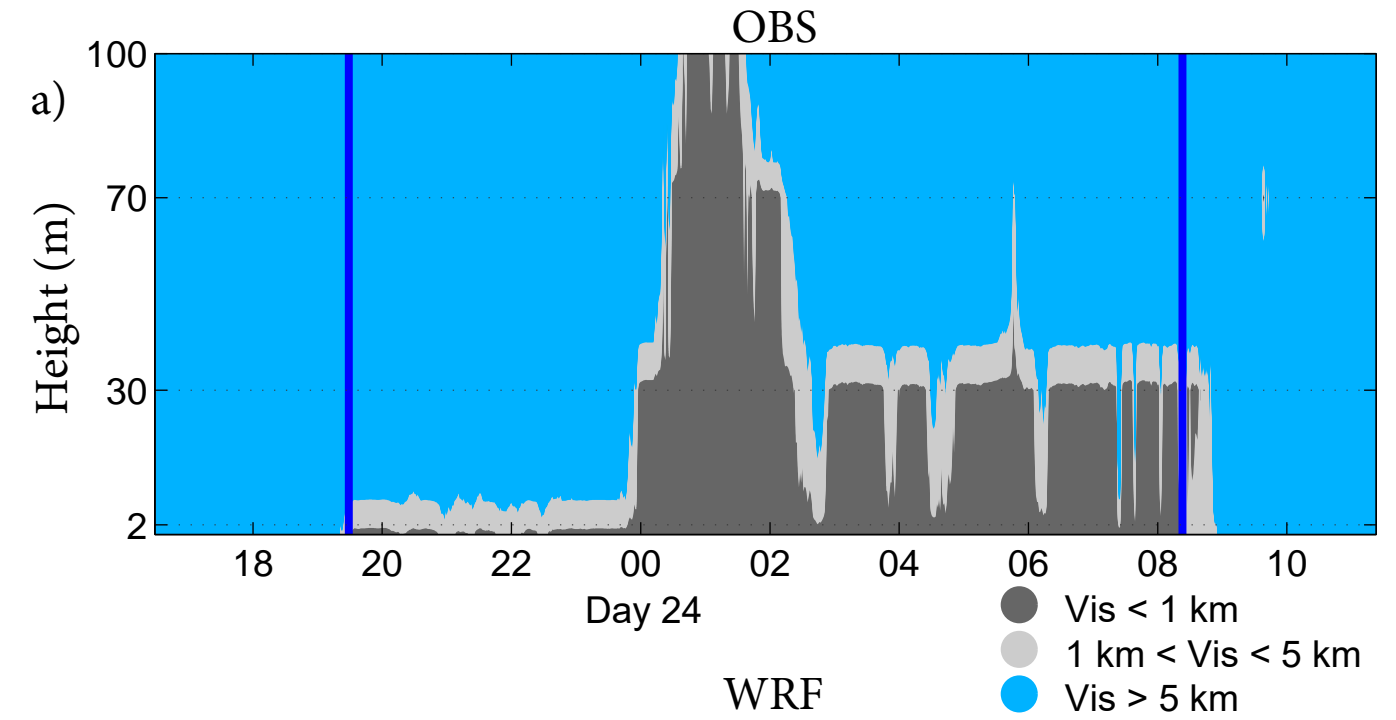

b)

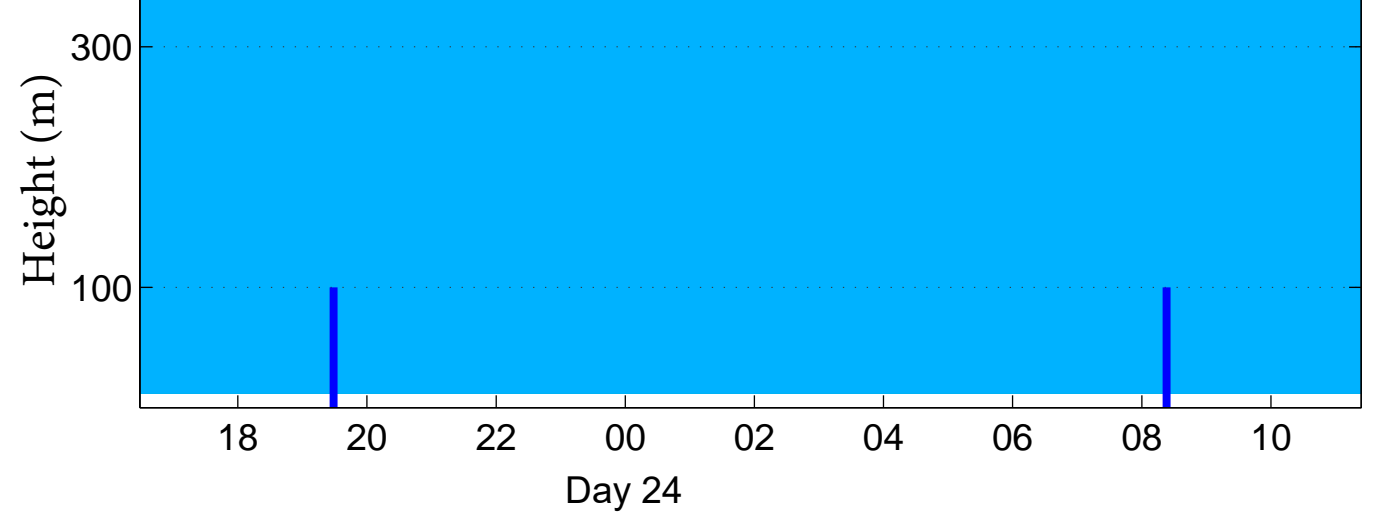

HAR

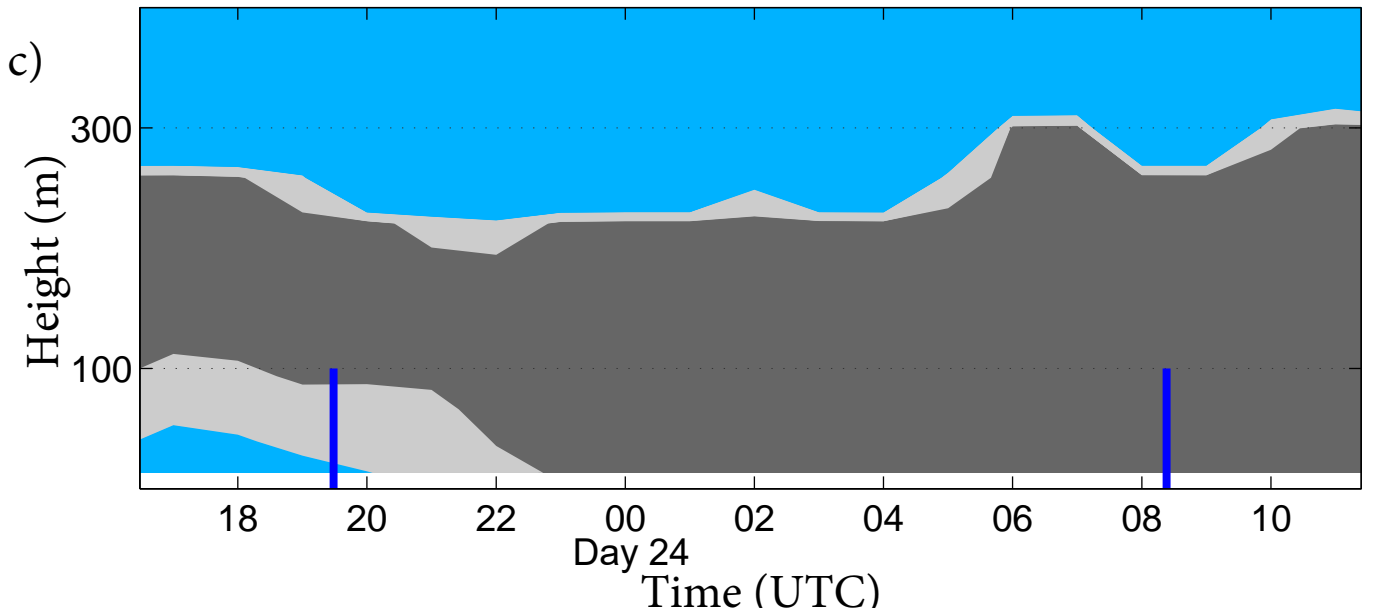

Figure 7: Idem than Figure 1 but for event 4, from 23/01 at 1929 UTC to 24/01 at 0824 UTC. 
a)

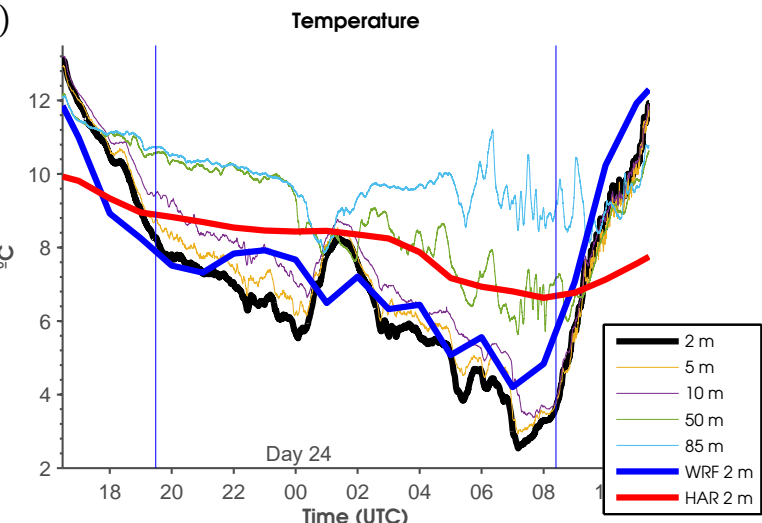

c)

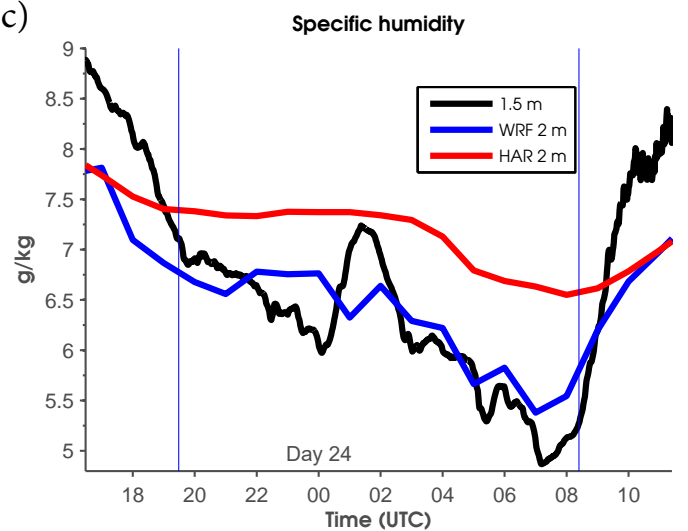

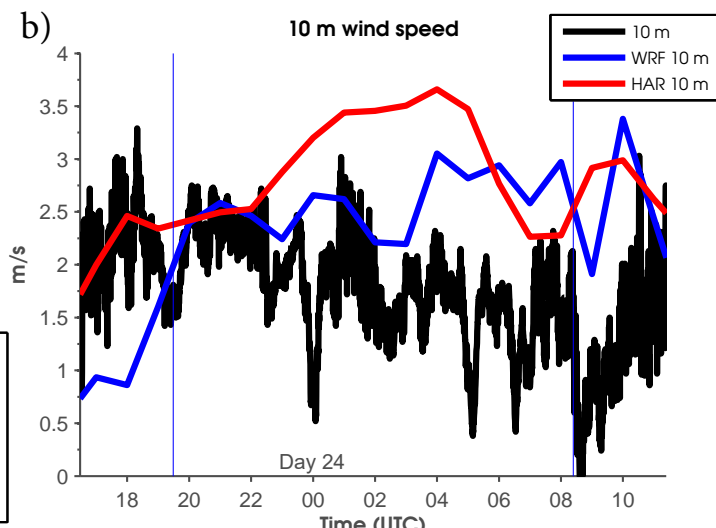

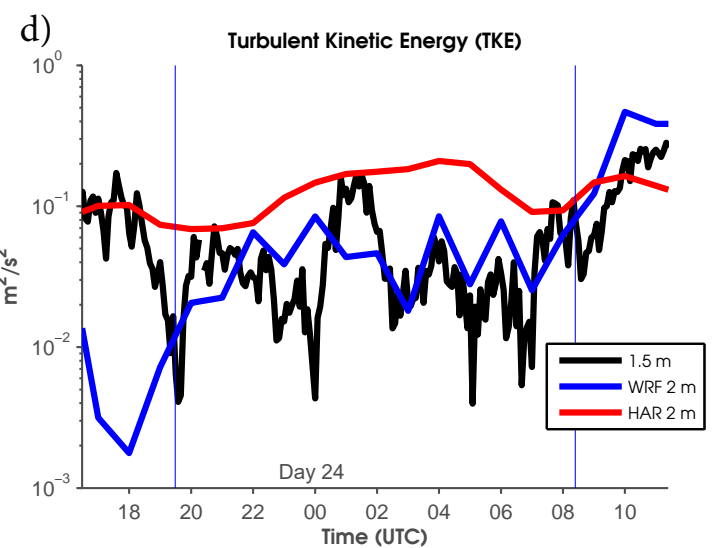

Figure 8: Idem than Figure 2 but for event 4, from 23/01 at 1929 UTC to 24/01 at 0824 UTC. 


\section{Horizontal Visibility}
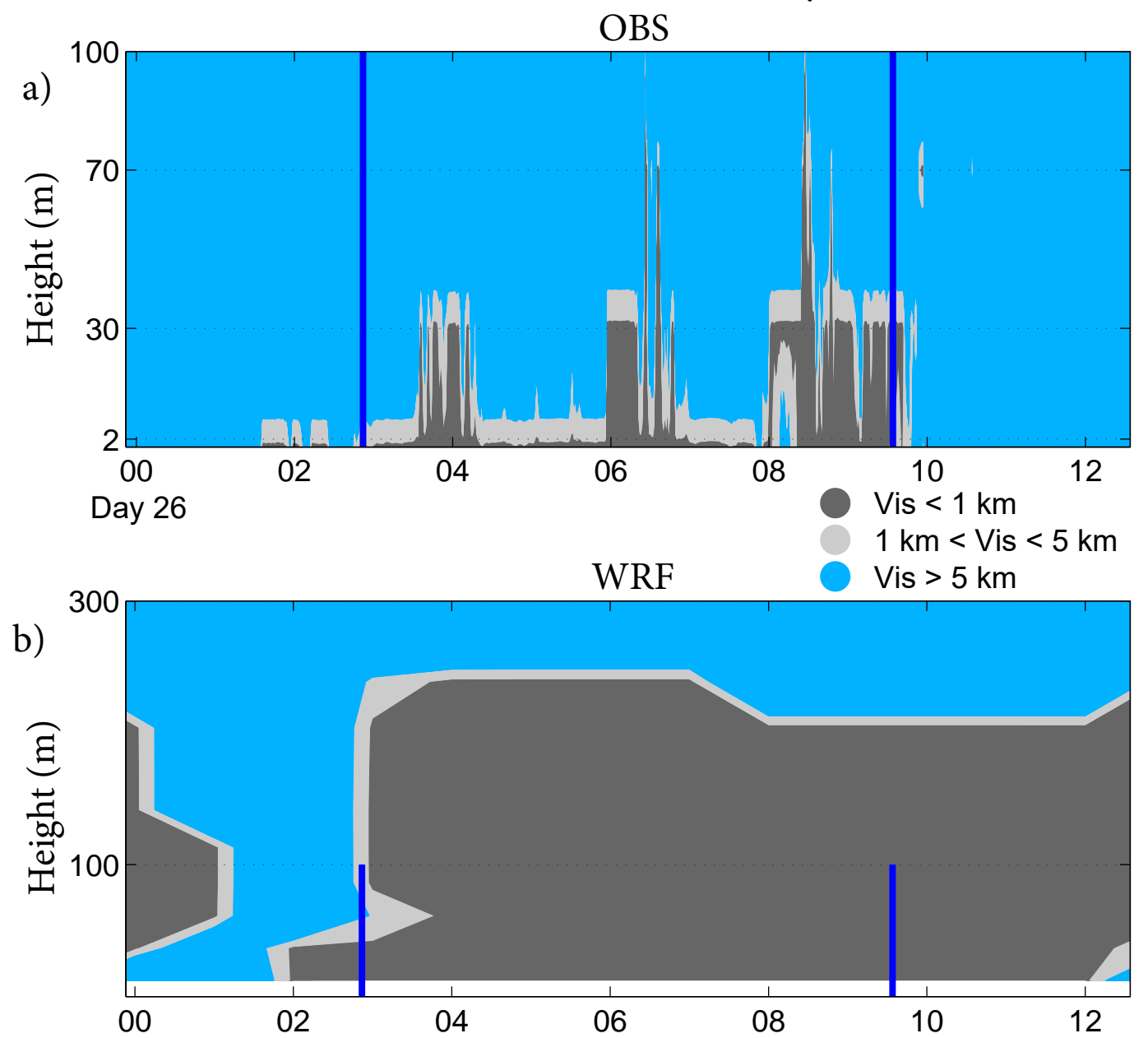

Day 26

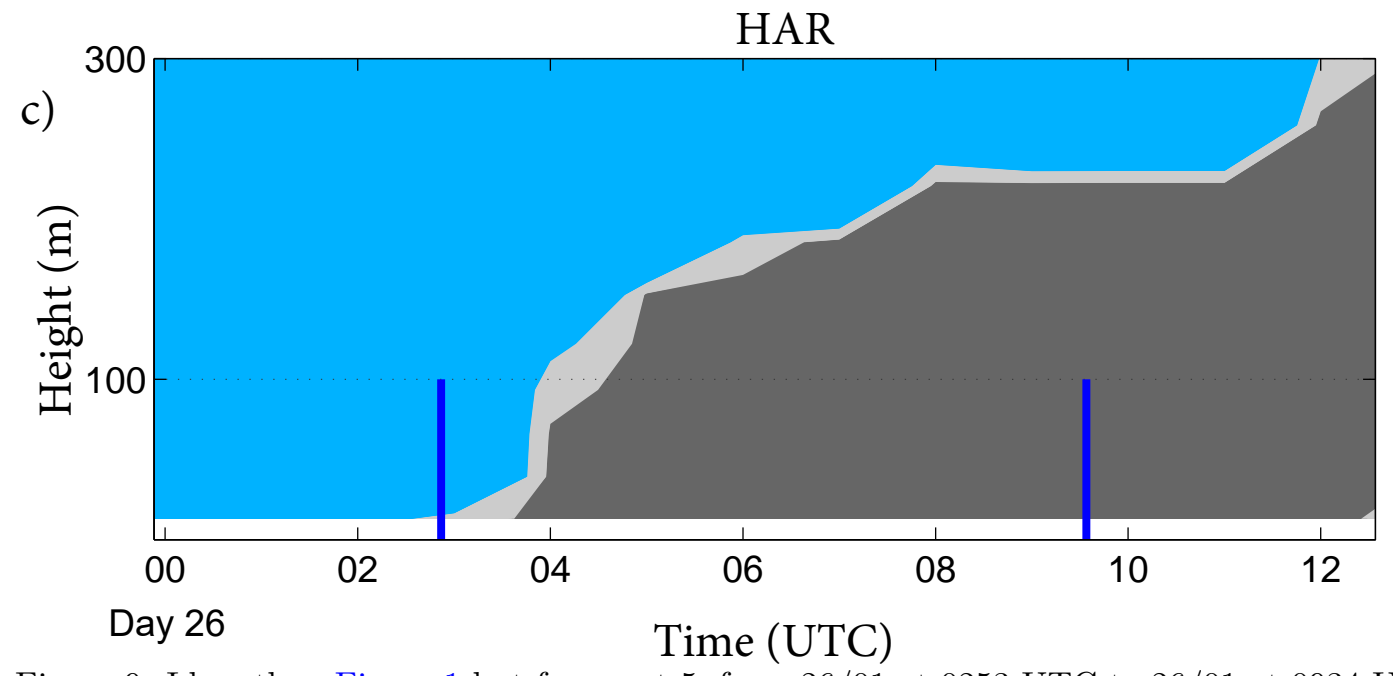

Figure 9: Idem than Figure 1 but for event 5, from 26/01 at 0253 UTC to 26/01 at 0934 UTC. 
a)

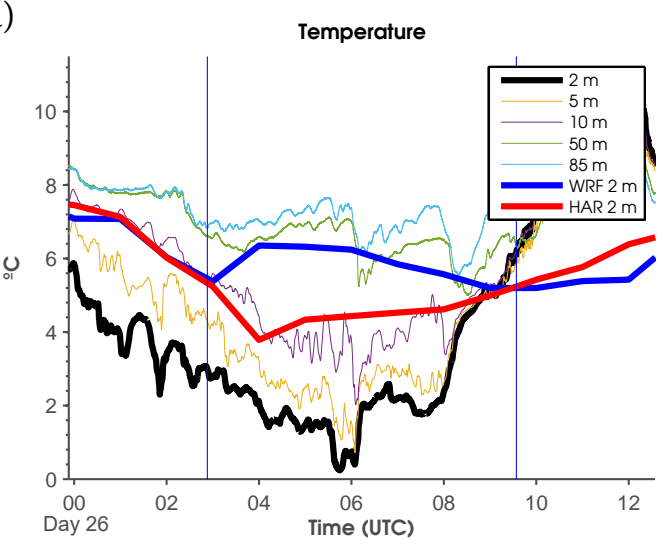

c)

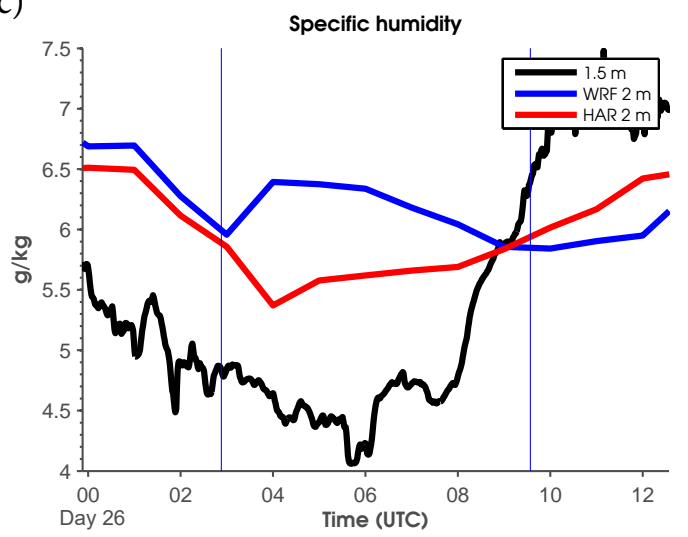

b)

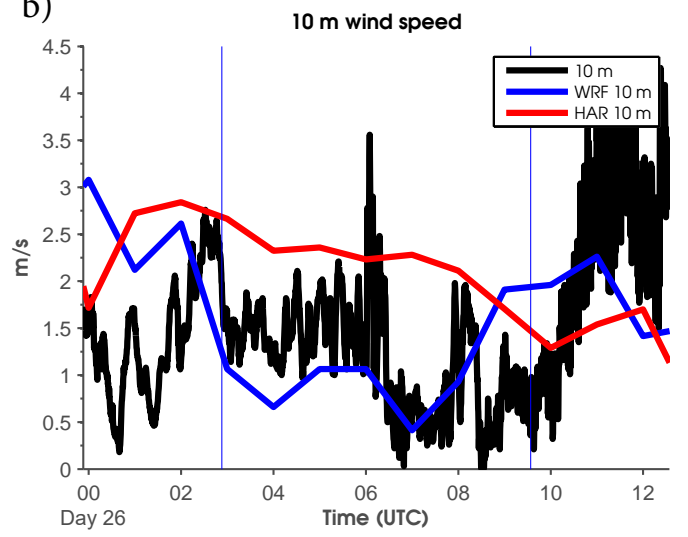

d)

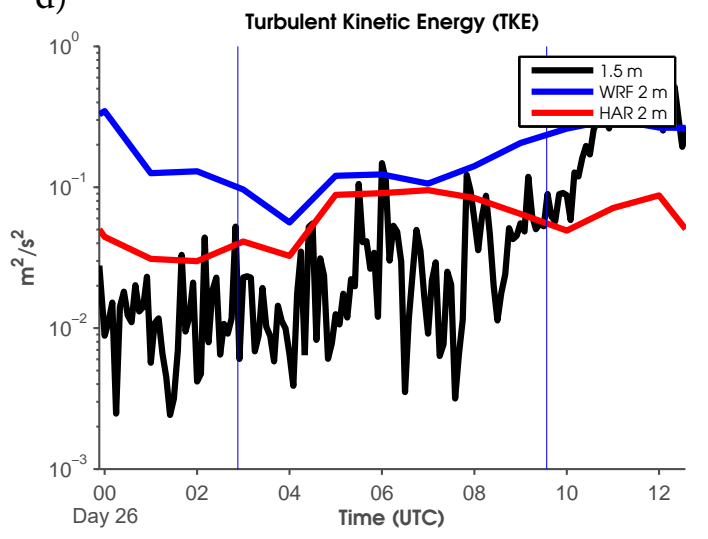

Figure 10: Idem than Figure 2 but for event 5, from 26/01 at 0253 UTC to 26/01 at 0934 UTC. 

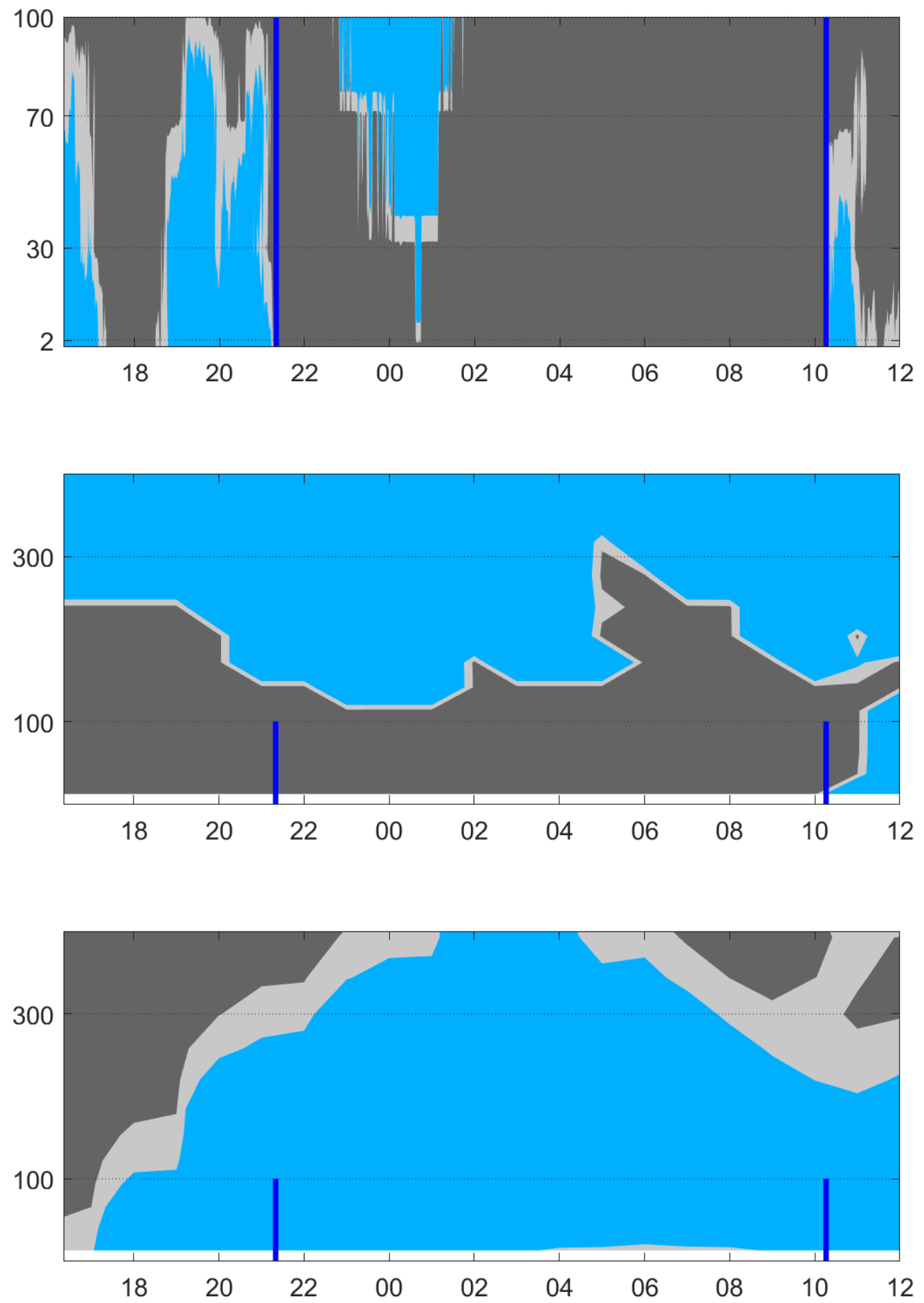

Figure 11: Idem than Figure 1 but for event 6, from 26/01 at 2121 UTC to 27/01 at 1016 UTC. 
a)

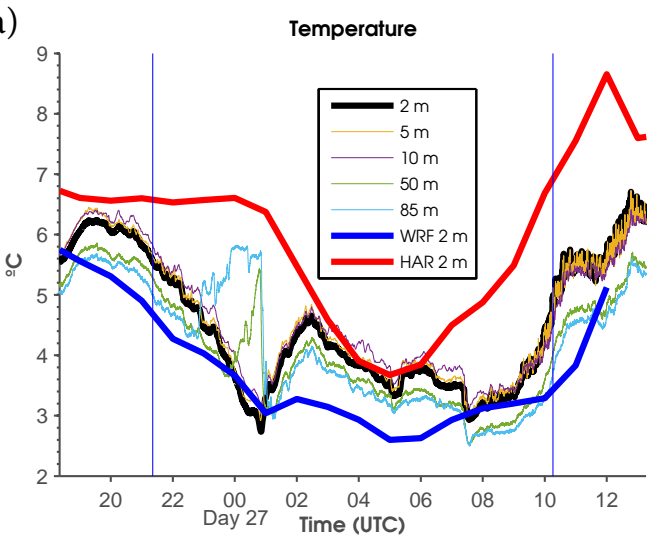

c)

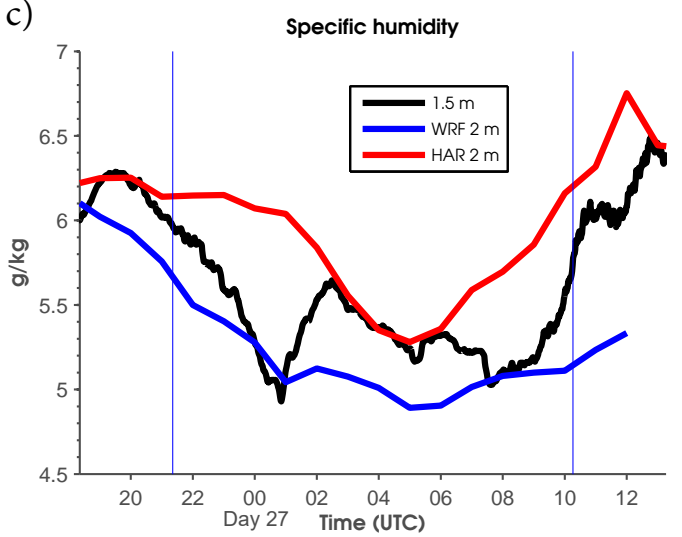

b) $10 \mathrm{~m}$ wind speed
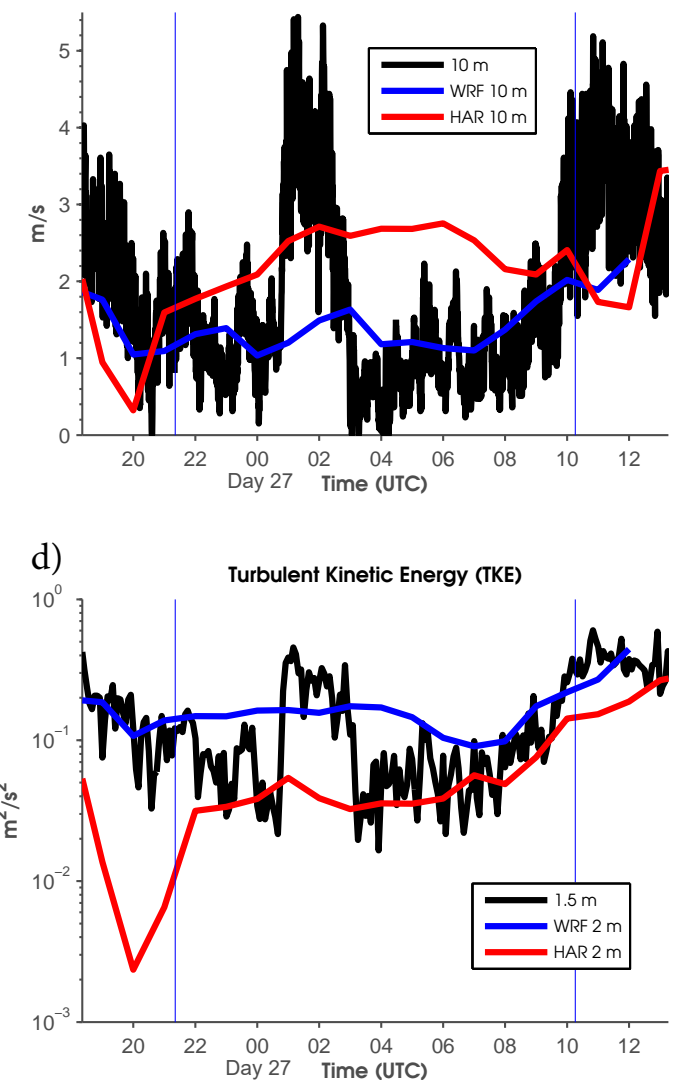

Figure 12: Idem than Figure 2 but for event 6, from 26/01 at 2121 UTC to 27/01 at 1016 UTC. 